DIW BERLIN

Discussion

Papers
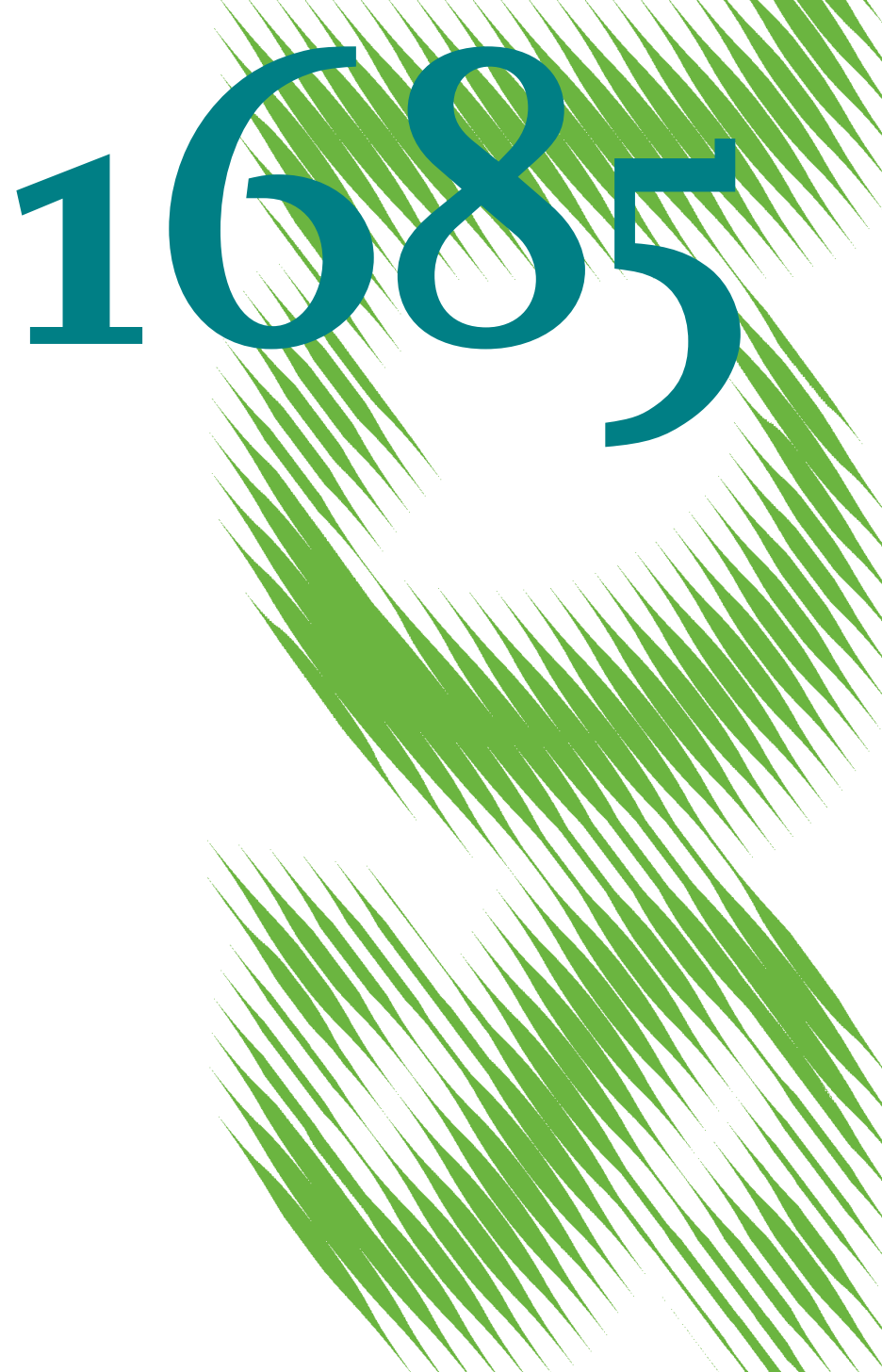

Abuse of Dominance and Antitrust Enforcement in the German Electricity Market 
Opinions expressed in this paper are those of the author(s) and do not necessarily reflect views of the institute.

IMPRESSUM

(C) DIW Berlin, 2017

DIW Berlin

German Institute for Economic Research

Mohrenstr. 58

10117 Berlin

Tel. +49 (30) $89789-0$

Fax +49 (30) $89789-200$

http://www.diw.de

ISSN electronic edition 1619-4535

Papers can be downloaded free of charge from the DIW Berlin website:

http://www.diw.de/discussionpapers

Discussion Papers of DIW Berlin are indexed in RePEc and SSRN:

http://ideas.repec.org/s/diw/diwwpp.html

http://www.ssrn.com/link/DIW-Berlin-German-Inst-Econ-Res.html 


\title{
Abuse of Dominance and Antitrust Enforcement in the German Electricity Market*
}

\author{
Tomaso Dusoł Florian Szücs; and Veit Böckers\$,
}

September 18, 2017

\begin{abstract}
In 2008, the European Commission investigated E.ON, a large and vertically integrated electricity company, for the alleged abuse of a joint dominant position by strategically withholding generation capacity. The case was settled after E.ON agreed to divest 5,000 MW generation capacity as well as its extra-high voltage network. We analyze the effect of these divestitures on German wholesale electricity prices. Our identification strategy is based on the observation that energy suppliers have more market power during peak periods when demand is high. Therefore, a decrease in market power should lead to convergence between peak and off-peak prices. Using daily electricity prices for the 2006 - 2012 period and controlling for cost and demand drivers, we find economically and statistically significant convergence effects after the implementation of the Commission's decision. Furthermore, the price reductions appear to be mostly due to the divestiture of gas and coal plants, which is consistent with merit-order considerations. Placebo regressions support a causal interpretation of our results.
\end{abstract}

Keywords: electricity, wholesale prices, EU Commission, abuse of dominance, ex post evaluation, E.ON JEL Codes: K21; L41; L94

\footnotetext{
${ }^{*}$ This paper is based on a study conducted for the Directorate General Competition of the European Commission. We thank Elena Argentesi, Marcus Asplund, Albert Banal-Estañol, Walter Beckert, Anette Boom, Adriaan Dierx, Fabienne Ilkovitz, John Kwoka, Axel Ockenfels, Peter Ormosi, Dinko Raytchev, Małgorzata Sadowska, Sebastian Schwenen, Jo Seldeslachts, Gregory Werden, Catherine Waddams, and seminar participants at CBS, DIW Berlin, and OECD as well as conference participants at the BECCLE, CRESSE, and EARIE conferences in 2017 for their valuable comments. Ivan Mitkov provided excellent assistance during the data collection. Tomaso Duso gratefully acknowledges support from the Berlin Centre for Consumer Policies (BCCP).

${ }^{\dagger}$ Corresponding author. Deutsches Institut für Wirtschaftsforschung (DIW Berlin), DICE Düsseldorf, Berlin Centre for Consumer Policies (BCCP), and CESifo. Mohrenstraße 58, 10117 Berlin, Germany. E-mail: tduso@diw.de. ${ }^{\ddagger}$ WU (Vienna University of Economics and Business), Welthandelsplatz 1, 1020 Vienna, Austria. E-mail: florian.szuecs@wu.ac.at.

${ }^{\S}$ CEG Germany GmbH, Research Affiliate DICE Düsseldorf
} 


\section{Introduction}

There is a substantial increase in the number of retrospective studies of the effects of competition policy enforcement on market outcomes. Developments in both the academic literature (e.g., Aguzzoni et al. (2016); Ashenfelter and Hosken (2010); Ashenfelter et al. (2014a,b); Kwoka (2013)) and the policy discussion (e.g., Ilkzkovitz and Dierx (2015); OECD (2016); Ormosi et al. (2015)) have helped to identify and define the best practices for ex post evaluation. However, the empirical evidence is not evenly spread across all areas of competition policy: while there is a large body of literature on the ex postevaluation of merger control and at least a number of studies on cartel enforcement, very little evidence exists on the effects of antitrust decisions pertaining to an abuse of market dominance (e.g. Davies and Ormosi (2012)). Moreover, the analysis of structural remedies is even scarcer, most likely due to difficulties in identifying and separating the effect of the antitrust infringement from that of the specific enforcement decision.

Contrary to its scant discussion in the empirical literature, allegations of an abuse of dominance are quite common. This is particularly true in wholesale electricity markets, which are more susceptible and vulnerable to the exercise of market power than other industries due to a few key economic characteristics. For one, demand is highly time-depended and inelastic. Moreover, electricity output electricity cannot be stored on an economically sufficient scale, which makes the design of an electricity market subject to peak-load pricing. ${ }^{1}$ Finally, the large fixed costs of energy production make this market particularly concentrated. The vulnerability of wholesale electricity markets to market power is documented in several empirical studies (e.g. Borenstein et al. (2002); Puller (2007) for the US market). ${ }^{2}$ A number of academic studies focusing on Germany (Möst and Genoese, 2009; Müsgens, 2006; Schwarz et al., 2007) analyze the 2002-2008 period and find that while prices were relatively high, there is insufficient empirical evidence to link this to an abuse of market power. ${ }^{3}$ Under the second package of the 2003 EU Directives, ${ }^{4}$ wholesale electricity

\footnotetext{
${ }^{1}$ For a comprehensive introduction and discussion see Boiteux (1960) and Stoft (2002).

${ }^{2}$ Using detailed firm-level data, Puller (2007) shows by mean of a structural model that some generators in the California market raised prices above the level predicted by a Cournot pricing game, but below the monopoly price, in 2000. Kwoka and Sabodash (2011) try to identify whether price spikes in energy markets can be interpreted as the result of strategic withholding by suppliers. They show that prices in the New York wholesale electricity market were particularly high during a period in 2001 due to strategic behavior. Finally, our paper also relates to the literature on strategic capacity withholding in wholesale electricity markets (e.g. Joskow and Kahn (2002)).

${ }^{3} \mathrm{~A}$ similar conclusion was reached by the German Federal Cartel Office in its wholesale electricity market inquiry (Bundeskartellamt (2011).

${ }^{4}$ Directive 2003/54/EC of the European Parliament and of the Council of 26 June 2003 concerning common rules for the internal market in electricity and repealing Directive 96/92/EC. (OJ L 176, 15.7.2003, p. 37 - 56).
} 
markets have been subject to structural remedies, mostly related to the unbundling of transmission and distribution networks. Ex post analyses of such remedies are also very scarce (Nardi, 2012). While there is some evidence on the effects of network unbundling, ${ }^{5}$ retrospective evaluations of structural remedies at the electricity generation stage do not exist to the best of our knowledge.

The primary goal of this paper is to close this gap and contribute to the emerging empirical literature on the ex post analysis of competition remedies in abuse of dominance cases. Secondly, we want to add to the discussion of the existence - and potential abuse - of market power in energy markets by providing an empirical analysis of one of the most important European competition landmark cases in the industry since liberalization. To this aim, we assess the impact of the abuse of dominance case brought by the European Commission (EC) against E.ON, the largest German utility company. In 2008, the EC alleged that E.ON was withdrawing available generation capacity from the German wholesale electricity market in order to raise prices and deter new investments in generation. Moreover, the Commission also raised concerns that E.ON may have favored its production affiliate for providing balancing services, while passing the resulting costs on to consumers, preventing other power producers from exporting balancing energy into its transmission zone. Despite contesting all the allegations, E.ON agreed to divest a total of 5,000 MW generation capacity as well as its ultra-high voltage transmission network and the case was settled.

We empirically analyze whether and how the shift in ownership of generation capacity that followed the divestitures affected wholesale electricity prices. Our identification strategy is based on the observation that energy suppliers have more market power during peak periods when demand is higher. Since the supply schedule is highly convex and much steeper during the peak period, shifts to a lower or higher capacity schedule would have much larger effects during peak times than off-peak times. Hence, we expect a convergence between peak and off-peak prices if market power is reduced, once other relevant factors such as electricity demand and supply drivers as well as the generation capacity from subsidized renewable resources are controlled for. We look at the evolution of daily German wholesale electricity prices as determined through the centralized energy exchange market, the EEX, over the 2006-2012 period. We find strong and statistically significant convergence effects after the implementation of the Commission's decision both in the short-run as well as in the long-run. The size of the effects is also economically relevant, with convergence varying between 5 to $11 € / \mathrm{MWh}$, which account for up to $36 \%$ of the gap between peak and off-peak prices.

We further distinguish the individual divestitures by technology type and find that only divestitures involving coal and gas plants entailed significant price reductions. This is consistent with

\footnotetext{
${ }^{5}$ For instance, Pollitt (2008) discusses the benefits of network unbundling but finds the empirical evidence to be insufficient to provide a reliable ex post analysis.
} 
the EC's theory of harm since, based on the technology types' merit order, precisely the capacity generated via coal and gas would have been strategically withheld. Placebo regressions based on data from six other European countries support our identification strategy as they show that the implementation of the remedies did not impact, or impacted to a much smaller extent, wholesale electricity prices in those markets. Similarly, placebo regressions using different timing for the occurrence of the treatment also support our identification strategy. In further robustness checks, we address issues of autocorrelation, change the frequency of the data, use different treatment windows, and define different peak-price periods. All checks corroborate our main findings. In sum, our findings support the view that the settlement, by affecting the extent of - and possibility to abuse of - market power in the German market had the effect of reducing the gap between peak and off-peak wholesale prices, a measure of profit margins and has, thusly, lead to lower prices for consumers. ${ }^{6}$

The paper proceeds as follows. Section 2 describes the functioning of the German electricity market. Section 3 presents the details of the case, while section 4 explains the econometric model and discusses a pricing equation for the German wholesale electricity market as well as the data and identification strategy. The main results and several robustness checks are presented in section 5. Section 6 then summarizes the findings and concludes.

\section{The German electricity market}

Since liberalization in the 1990s, the German electricity sector is characterized by a vertical supply chain consisting of a generation stage, a wholesale market, a transmission (higher voltages of 220$380 \mathrm{kV}$ ) grid, a distribution (lower voltages of 20-110 kV) grid, and a retail market (see figure 1). While the wholesale and retail level have been substantially opened up to competition, the network infrastructure is still regulated. Finally, a parallel balancing market ensures constant equilibrium between actual production and consumption.

Historically, German power supply was provided by fossil-fueled generation. In the early 2000s, comprehensive subsidization schemes for renewable power sources were introduced and their market share quickly rose from $8 \%$ in 2003 to $30 \%$ in 2015 (BDEW, 2016). However, this rapid expansion was not due to market forces, but rather due to the regulatory environment. Specifically, it was determined by two factors: i) prioritized feed-in of renewables - especially the two predominant types of wind and photovoltaic generation - and ii) the monetary compensation via a regulated price mechanism. Hence, both this regulatory framework as well as the random nature of resource

\footnotetext{
${ }^{6}$ Indeed, Duso and Szücs (2017) show that changes in German electricity wholesale prices are, to a substantial degree, passed on to consumers.
} 
Figure 1: The Structure of the German Electricity Market

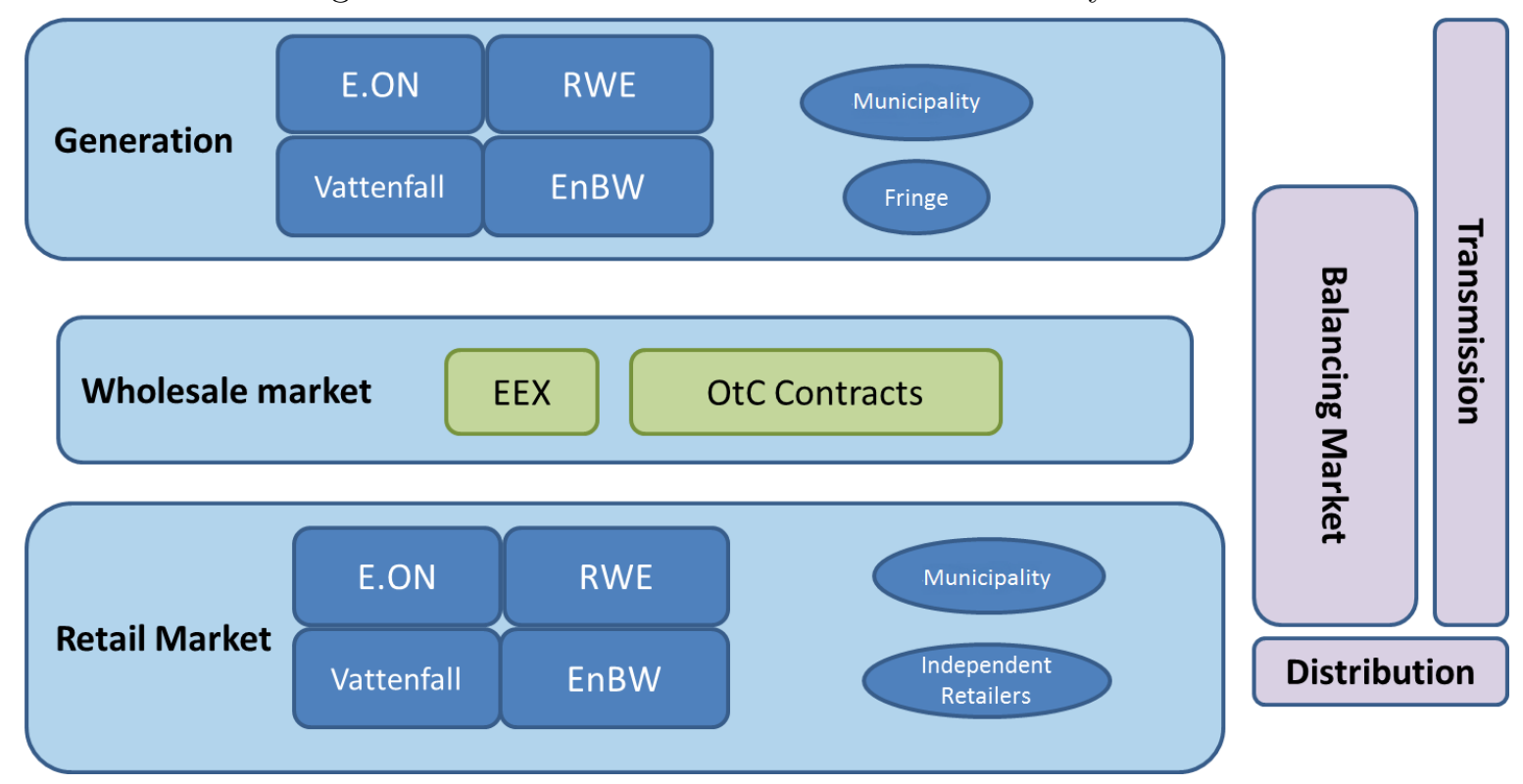

availability of wind and solar render renewable electricity supply to be a quasi-exogenous supplyshock in the market system. Consequently, this is a crucial element to control for in our analysis of price dynamics, as power produced from wind and photovoltaic significantly impacts wholesale prices, especially during peak hours, which are key to our identification strategy.

Our study focuses on the price effects due to changes in the conventional, fossil-fuel based generation as this generation capacity is the most relevant in terms of market power abuse. Conventional generation is dominated by four large vertically integrated - though legally unbundled - companies: E.ON (now split into E.ON SE and Uniper SE), RWE, Vattenfall, and Energie Baden-Württemberg $(\mathrm{EnBW})$, who are also the main players in the retail market and have historically owned large parts of the transmission network. ${ }^{7}$

In 2004, the European Commission (Case No COMP/M.4110 - E.ON / ENDESA pg. 10) reported that "[b]y far the largest proportion of electricity in Germany is generated by four vertically integrated energy suppliers: E.ON, RWE, Vattenfall and EnBW. In generation (installed capacity) RWE Power is market leader, with a [30-40\%] market share (2004 data), followed by E.ON ([20-30\%]), Vattenfall ([10-20\%]) and EnBW ([10-20\%]). Other companies jointly represent [1020\%]".âĂ This picture remained quite stable over the subsequent years. In its sector inquiry in 2011 (Bundeskartellamt (2011), the German Federal Cartel Office (FCO) reported that the German

\footnotetext{
${ }^{7}$ Since 2007, the regulatory framework requires vertically integrated energy suppliers to legally unbundle from system operators. Suppliers serving fewer than 100,000 customers are exempt from this regulation.
} 
electricity market is (still) characterized by joint dominance. The shares of net electricity of the four big players for the years 2007, 2008, and 2009 are reported in table 1.

Table 1: Market share of the big four energy companies 2007-2009

\begin{tabular}{lcccccc}
\hline & \multicolumn{3}{c}{ Generated Capacity } & \multicolumn{3}{c}{ Total Electricity Feed-in } \\
& 2007 & 2008 & 2009 & 2007 & 2008 & 2009 \\
\hline \hline RWE & $34 \%$ & $33 \%$ & $31 \%$ & $35 \%$ & $36 \%$ & $31 \%$ \\
E.ON & $23 \%$ & $23 \%$ & $19 \%$ & $23 \%$ & $22 \%$ & $21 \%$ \\
Vattenfall & $17 \%$ & $16 \%$ & $16 \%$ & $17 \%$ & $15 \%$ & $16 \%$ \\
EnBW & $12 \%$ & $12 \%$ & $14 \%$ & $12 \%$ & $11 \%$ & $14 \%$ \\
Market Volume & 94,433 & 95,756 & n.r. & 467.9 & 465.1 & n.r. \\
\hline \hline
\end{tabular}

Source: Bundeskartellamt (2011)

Even in 2014, when generation from renewable sources accounted for over a quarter of production, these four dominant companies still accounted for more than two-thirds of electricity production. The remaining German energy demand is covered by a large number of municipal operators ('Stadtwerke') and other smaller producers as well as imports.

While market shares are an important indicator for the existence and extent of market power, they may be less relevant in markets with highly inelastic demand, such as wholesale energy. Here, even firms with relatively small market shares can play a pivotal role and find it profitable to withdraw capacity with the aim of increasing prices. Still, this strategy is most attractive (and practicable) for suppliers with a diverse power plant portfolio. Following this logic, the FCO's investigation in 2014 not only looked at market shares of the alleged dominant firms, but also applied additional quantitative tests to analyze the extent of market power in energy markets.

Based on the results of this analysis, the FCO stressed that all four big players in the German wholesale energy markets in 2007-2008 were "in a position to behave to an appreciable extent independently of their competitors, customers and ultimately of their consumers and to restrict competition on the first-time sales market .... Each of these undertakings was essential for meeting Germany's electricity demand in a considerable number of hours"(Bundeskartellamt (2011), pg. 6). The FCO also indicated that the market power of the big four was expected to decline as the result of the implementation of the remedies imposed by the EC on E.ON and by the economic crisis. Nevertheless, they still expected joint dominance to persist in the German wholesale electricity market. $^{8}$

\footnotetext{
${ }^{8}$ The FCO's Decision Division did not reach a clear conclusion on whether the observed power plant operational management constitutes evidence of abusive capacity withholding or, rather, the consequence of "objective reasons for not operating power plants whose marginal costs are lower than the day-ahead spot market price" (Bundeskartellamt (2011), pg. 6). Consequently, the FCO concluded that "the non-operation of profitable power
} 
In wholesale electricity markets, most of the generated electricity is sold either internally to the retail outlets of the vertically integrated producers or sold to other retailers via bilateral, over the counter (OTC) contracts as well as centralized energy exchange markets, such as the European Energy Exchange (EEX; currently in partnership with EPEX, European Power Exchange). Still, most of energy trade between wholesalers and retailers in Germany is done by means of OTC (longterm) bilateral contracts between producers and suppliers, with only a minor, albeit increasing, percentage of energy trade covered through the EEX. ${ }^{9}$ In spite of its relatively low share in total market transactions, the electricity price determined at the power exchange serves as a reference price for the market as a whole due to potential arbitrage opportunities. Therefore, the overall price effects of anti-competitive behavior or structural remedies should be reflected in the power exchange prices and, consequently, quantifiable by analyzing the evolution of the EEX prices.

\section{The Case}

In 2008, the European Commission investigated claims about E.ON withdrawing available generation capacity from the German wholesale electricity market in order to raise prices and deter new investment in generation. The investigation confirmed the presence of competition concerns. Consequently, E.ON agreed to divest a total of 5,000 MW of generation capacity and the case was settled. ${ }^{10}$ Figure 2 illustrates the location of the plants concerned, whereby the sizes of the circles represent the volume of the divestitures. While the Commission's decision was announced in 2008, the remedies were implemented during the subsequent years. Specifically, the various plants were sold to different buyers between January 2009 and May 2010.

At the same time, the Commission raised the concern that E.ON may have favored its production affiliate for providing balancing services, while passing the resulting costs on to consumers, thus preventing other power producers from exporting balancing energy into its transmission zone. To address the Commission's concerns in the electricity balancing market, E.ON committed to divest its ultra-high voltage network. This divestiture also took place in early 2010. The timing and details of the individual divestitures are summarized in table 2.

plants identified in the present inquiry is too limited to initiate specific abuse proceedings with respect to the period examined" (Bundeskartellamt (2011), pg. 6).

${ }^{9}$ For instance, Ockenfels et al. (2008) report that only $15 \%$ of energy consumption was traded at the EEX in 2008. A 2013 EEX press release mentions that the share of EEX in the German market rose to 20\% (EEX, 2013) and in 2015 increased further up to $30 \%$ (EEX, 2015).

${ }^{10}$ As noted by Sadowska (2011), the E.ON case has to be considered a "commitment decision." The Commission, pursuant to Article 9, neither demonstrated nor confirmed the existence of a dominant position or an abuse, but it simply made the undertakings' commitments binding. This has important policy implications. Specifically, Sadowska (2011) discusses the advantages but also the substantial drawbacks of commitment procedure in antitrust cases. 
Figure 2: Capacity-weighted location of divestitures

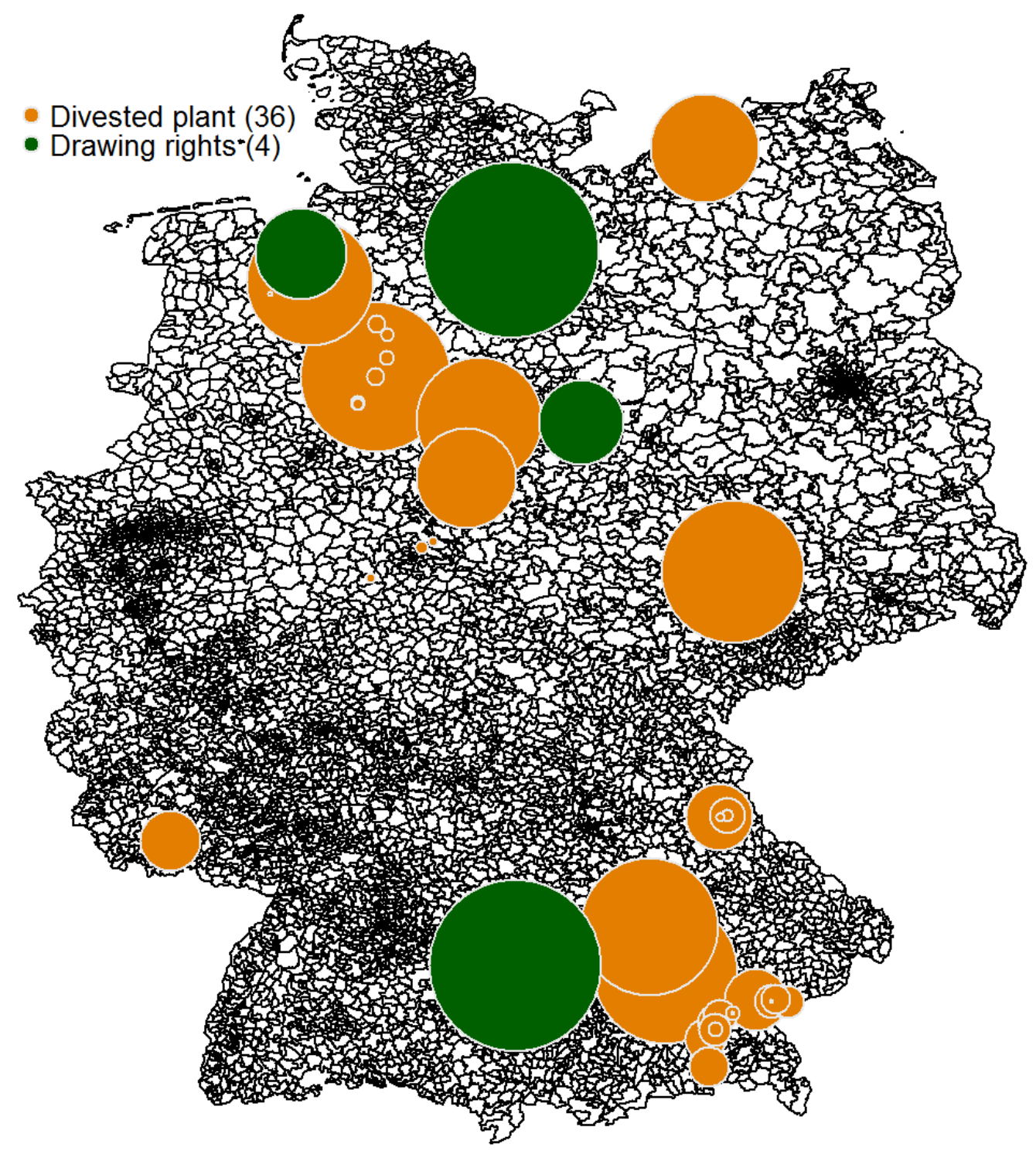

Source: Information provided by EC. 
Table 2: Date and details of divestitures

\begin{tabular}{llcccl}
\hline Date & Buyer & \# of plants & Capacity MW & Technology & Remedy \\
\hline \hline 01.01.2009 & Statkraft & 12 & 753 & water and gas & divest \\
11.04.2009 & Electrabel & 6 & 931 & water and coal & divest \\
31.05.2009 & EnBW & 2 & 525 & coal & divest \\
31.08 .2009 & Verbund & 13 & 312 & water & divest \\
19.10 .2009 & Electrabel & 3 & 1500 & nuclear & drawing rights \\
01.01 .2010 & EnBW & 3 & 760 & coal & divest \& \\
& SW Hannover & & & & drawing rights \\
25.02 .2010 & TenneT & $1(+$ grid $)$ & 415 & gas & divest \\
03.05 .2010 & Morgan Stanley & 2 & 265 & coal & divest \\
\hline \hline
\end{tabular}

Source: Information provided by $E C$.

Cumulatively, the Commission decisions affected two main product markets: the German wholesale energy market and the balancing energy market. We will concentrate on the former and, in what follows, we briefly explain why we think that this is a reasonable approach.

Balancing markets are ancillary mechanisms that are key for a well-functioning energy market as they ensure that consumption is equal to production in real time. In Germany, electricity generators are required to reserve a fraction of their capacity for the transmission system operators, which they can use to restore frequency in the electricity grid (Haucap et al., 2012). Wholesale electricity markets and balancing markets should be expected to be related as there exist arbitrage opportunities between the spot market and the balancing mechanism (Just and Weber, 2015). Indeed, prices in the balancing markets (capacity prices) constitute a sort of opportunity cost for energy suppliers who commit themselves not to use the reserved capacity on wholesale spot markets. Therefore, abuse in the balancing market might be expected to affect competition on the wholesale level.

However, empirical evidence for the German market suggests that this relationship is of secondorder importance. Just and Weber (2015) quantify the effect of strategic arbitrage behavior between the German wholesale and balancing markets and find relatively modest effects. ${ }^{11}$ Thus, although

\footnotetext{
${ }^{11}$ Specifically, they find a "clear tendency that market participants use the arbitrage opportunity to fulfil their supply commitment with relatively cheap balancing energy when spot prices are relatively high, and vice versa. In periods with intraday spot prices above $120 € / \mathrm{MWh}$, the control zones are predominantly undersupplied. The Amprion control zone is undersupplied in $75 \%$, and the GCC control zone in $80 \%$ of those $641 / 4$-hours, with an average imbalance of $-267 \mathrm{MW}$ and $-488 \mathrm{MW}$, respectively. The opposite is true for prices roughly below -20 $€ /$ MWh with Amprion being oversupplied in $77 \%$ with an average of $501 \mathrm{MW}$ and GCC in $74 \%$ of those 196 1/4-hours with $819 \mathrm{MW}$ on average. It should be noted that imbalances did not exceed the contracted reserve capacity and that periods with extreme spot prices were not overly exploited as the incentives might suggest" (Just and Weber, 2015).
} 
the effect of unbundling in the balancing market might be important in the long-run, we consider it to be of second-order when compared to the direct effect of the potential abuse in the wholesale market, particularly in the short-run. Consequently, we focus on the evaluation of the first part of the decision, i.e. the alleged abuse of dominant position in the wholesale electricity market. Specifically, we try to isolate the effect of the implementation of the individual capacity divestitures. Yet, we are unable to separate the different effects from the two parts of the decision, especially with a regard to the long-run implications. Moreover, given that the divestiture of the network grid was implemented jointly with the divestiture of some of the E.ON's capacity, even the most disaggregated analysis could not hope to separately identify the effects of the two remedies. Hence, our empirical measurement will be the cumulative effect of both parts of the decision.

\section{The Econometric Analysis}

From a theory point of view, the effect of the Commission's decision on wholesale prices is straightforward. The divestiture of generation capacity should lead to an increase in competition since the production facilities were mostly purchased by medium-sized players in the power generation market. This, in turn, causes an outward shift of the energy supply-curve. Subsequently, wholesale prices should, ceteris paribus, decrease.

Still, identification and empirical measurement of the impact is difficult since there are both several demand-side and supply-side factors that may be correlated with the Commission's decision and must be controlled for. As a structural approach is not feasible with the data available, we adopt the logic of a difference-in-difference (DiD) framework to identify the causal effect of the Commission's decision. The effect of the policy intervention is then identified by comparing a 'treatment' group, which is affected by the policy intervention, to a 'control' group, which is not (or to a lesser extent) affected.

An important challenge in the implementation of such a framework is the choice of a suitable control group, which is at the same time comparable to the treatment group and unaffected by the treatment. For this case study, we adopt a strategy based on a within-country comparison. We contrast two different outcomes in Germany - the peak and off-peak wholesale electricity prices which we expect to be affected differently by the policy decision. Specifically, while during peaktimes firms can sustain significant mark-ups over the marginal cost of energy production and, hence, the extent of market power plays a significant role in determining equilibrium prices, off-peak prices essentially reflect the marginal cost of the high-cost plants/technology and are, thus, unaffected by a reduction of market power.

These different price regimes constitute the treatment and control groups in our DiD-framework. 
Looking at the different evolution of the two outcomes before and after the implementation of the divestitures, we expect to identify the causal effect of the Commission's decision. One of the main advantages of this approach is that the performance of the two groups is equally affected by their common institutional, cost, and demand drivers. Hence, there is less reason to worry about differences across the two groups, which would likely occur in a cross-country comparison. To put it differently, the common trend assumption is more likely to hold conditional on adjusting for the most crucial drivers of peak and off-peak prices. To control for these different dynamics, we will use demand and supply conditions that are different between peak and off-peak periods.

\subsection{The basic framework}

The basic empirical model that we use to analyze the German wholesale energy market consists of a price equation, based on Böckers and Heimeshoff (2014), where the wholesale price is a function of demand and supply drivers:

$$
\begin{array}{r}
p_{i t}=\alpha+\beta \text { treat }_{i}+\gamma \text { post }_{t}+\delta \text { treat }_{i} \times \text { post }_{t}+\alpha_{1} \text { wind }_{i t}+\alpha_{2} \text { wind }_{i t}^{2}+\alpha_{3} \operatorname{sun}_{i t}+\alpha_{4} \operatorname{sun}_{i t}^{2} \\
+\alpha_{5} \text { solar_cap }_{t}+\alpha_{6} \text { wind_cap }_{t}+\alpha_{7} \text { temp }_{i t}+\alpha_{8} \text { temp }_{i t}^{2}+\alpha_{9} \operatorname{cb}_{i t}+\alpha_{10} \text { coupling }_{t} \\
+\alpha_{11} \text { ind_prod } \\
t
\end{array}
$$

The daily power price $p_{i t}$, at day $t$, for group $i$ - peak and off-peak - is regressed on a treatment (i.e. peak-price) indicator $\left(\right.$ treat $\left._{i}\right)$, an indicator for the evaluation period $\left(\text { post }_{t}\right)^{12}$ as well as the interaction of the two, which measures the treatment effect. Further, we include a large number of supply and demand drivers such as: variables indicating the daily amount of energy produced from wind $\left(\operatorname{wind}_{i t}\right)$ and the daily amount of sunshine in minutes $\left(\operatorname{sun}_{i t}\right)$, both in linear and quadratic form as well as separately for peak and off-peak periods; a variable indicating the (day-specific) total solar and wind capacity installed in Germany (solar_cap and wind_cap $_{t}$ ); the daily average temperature in the peak and off-peak time periods $\left(\operatorname{temp}_{i t}\right)$, in both linear and quadratic form to account for the non-linear relationship between temperature and power consumption as well as the relationship between temperature and power production; ${ }^{13}$ daily net cross-border energy flows during peak and off-peak periods $\left(\mathrm{cb}_{i t}\right)$; an indicator variable for market coupling with Denmark after November 2009 as well as an indicator for market integration with Belgium, France, Holland and the Scandinavian countries after November 2010 ( coupling $_{t}$ ); a monthly industrial production index, which acts as a control for energy demand from industrial customers (ind_prod ${ }_{t}$ ) as well

\footnotetext{
${ }^{12}$ In some specifications of the evaluation period, the post-indicator is collinear with the included year fixed effects and, thus, dropped from estimation.

${ }^{13}$ See for example Engle et al. (1992) and Pardo et al. (2002).
} 
as proxy for the business cycle; an indicator variable for holidays, when business activities are low $\left(\right.$ holiday $_{t}$ ) and input prices such as the daily price of oil, gas and $\mathrm{CO}_{2}$ emissions as well as weekly coal and uranium prices. Additionally, we include fixed effects for the day of the week (Mo - Sun), months (Jan - Dec), and years (2006 - 2012).

Finally, the error terms are assumed to be auto-correlated and heteroskedastic. We, therefore, estimate Newey-West standard errors and assume the maximum lag order of autocorrelation to be equal to one week (seven days). Since the assumptions on the error term play a crucial role for making accurate inference, we perform several robustness checks to test their relevance, which we discuss in the results section.

The definitions of the treatment and post-period indicators are discussed in the next sections. The double differencing implied by a DiD framework as well as the inclusion of a large set of demandside and supply-side drivers helps mitigating endogeneity problems due to omitted variables and increase confidence in the causal nature of the estimated effect.

\subsection{Data}

The data for the analysis of wholesale prices come from different sources. The hourly electricity prices are obtained from the EEX in Leipzig and aggregated to the daily level for peak and offpeak periods separately. Temperature data during peak and off-peak periods in degree Celsius as well as data on daily sunshine duration in minutes are obtained from the German Weather Service (dwd.de). As data on daily photovoltaic generation is not available on a daily basis before 2010, we use daily sunshine duration to proxy for solar production. ${ }^{14}$ Additionally, we collect data on the installed solar and wind capacities from https://data.open-power-system-data.org/.

Data on electricity generation from wind as well as data on cross-border energy flows with all neighboring countries are retrieved from the websites of the four network operators (50 Hertz, Amprion, TenneT, and TransnetBW). The industrial production index is obtained from https://www.sachverstaendigenrat-wirtschaft.de/. The oil price index is chosen from ICE Brent Europe (in US $\$$ /tonne) and the gas price reference is that of ENDEX/TTF. Uranium prices were obtained from www.uxc.com. The coal price is a combined price series of two sources (Platts and Argus McCloskey), which is adequate since they are extremely highly correlated and both measure the daily European reference price for coal imports into North-western Europe. The emission price is the weighted emission certificate price from the EEX.

\footnotetext{
${ }^{14}$ To assess the quality of the proxy variable, we used post-2010 solar production data from the four network operators and estimated the following regression: solar $_{t}=\sigma_{0}+\sigma_{1}$ sun $_{t}+\sigma_{2}$ solar $_{-}$cap $t+\zeta \operatorname{month}_{t}+\varepsilon_{t}$. Since the model fits the data very well $\left(R^{2}=0.86\right)$ and the model predictions highly correlate with actual solar production $(\rho=.93)$, we conclude that daily sunshine duration and solar capacity adequately proxy for solar production.
} 
The sample ranges from 2006 to $2012^{15}$ and contains two observations (peak and off-peak) per day. The data are summarized in table 3.

Table 3: Summary statistics of the dataset

\begin{tabular}{lccccc}
\hline Variable & Obs & Mean & Sdt. Dev. & Min & Max \\
\hline \hline Price & 5114 & 46.61 & 22.2 & -131 & 508 \\
Price peak & 2557 & 56.01 & 25.3 & -7 & 508 \\
Price offpeak & 2557 & 37.22 & 13.0 & -131 & 81 \\
Temperature peak & 2557 & 12.33 & 8.2 & -11 & 33 \\
Temperature offpeak & 2557 & 8.47 & 6.6 & -13 & 24 \\
Cross-border flows peak & 2557 & -469.45 & 1693.5 & -5702 & 6040 \\
Cross-border flows offpeak & 2557 & 4651.96 & 18135.5 & -27645 & 124474 \\
Wind peak & 5114 & 4811.61 & 3953.2 & 225 & 22053 \\
Wind offpeak & 5114 & 4410.40 & 3448.3 & 376 & 22927 \\
Minutes of sun, peak & 5114 & 227.96 & 178.1 & 0 & 683 \\
Minutes of sun, offpeak & 5114 & 56.06 & 68.2 & 0 & 284 \\
Wind capacity & 5114 & 22.02 & 3.4 & 16 & 29 \\
Solar capacity & 5114 & 11.42 & 9.4 & 2 & 33 \\
Industrial production index & 5114 & 102.82 & 7.1 & 84 & 112 \\
Oil price & 5114 & 85.54 & 23.9 & 34 & 144 \\
Gas price & 5114 & 19.62 & 5.9 & 4 & 53 \\
Uranium price & 5114 & 58.44 & 20.3 & 36 & 136 \\
Coal price & 5114 & 96.32 & 32.1 & 53 & 225 \\
Emission price & 5114 & 9.31 & 7.0 & 0 & 30 \\
& & & & & \\
\hline \hline
\end{tabular}

\subsection{Identification of the Treatment Group}

The proposed identification strategy is based on the different price response to the Commission's decision between peak (8am-8pm) and off-peak prices (9pm-7am). ${ }^{16}$ Thus, the treatment is defined by the following dummy variable:

$$
\text { treat }_{i}= \begin{cases}1 & \text { if peak demand } \\ 0 & \text { if off-peak demand }\end{cases}
$$

The logic of our identification is graphically explained in Figure 3. The underlying idea is

\footnotetext{
${ }^{15}$ All our findings are robust to excluding 2012 from the sample, when Germany's electricity markets might have been affected by the aftermath of the 2011 Fukushima disaster.

${ }^{16}$ In section 6.3 we thoroughly discuss the definition of peak time and present the results for several specifications based on various definitions.
} 
Figure 3: Effect of a shift in supply during peak and off-peak demand

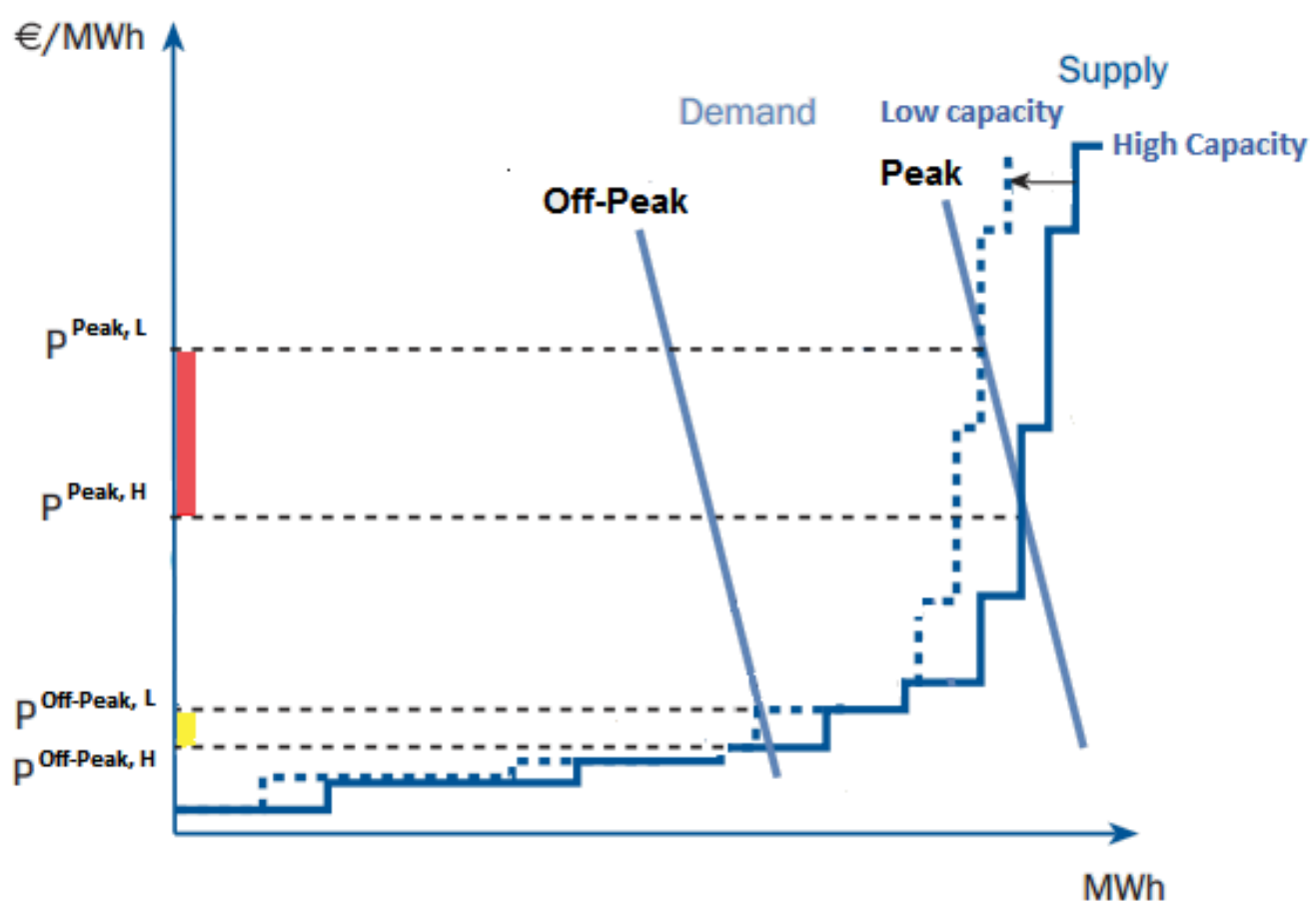

that energy suppliers have more market power during peak periods where demand is higher due to business activities. Since the supply schedule is highly convex and much steeper in the peak period (due to the merit order of the underlying fuel types), a shift to a lower capacity schedule through capacity withdrawal from the market has a much larger effect during the peak time. ${ }^{17}$ The difference in the peak price between the high capacity scenario $\left(P^{P e a k, H}\right)$ and the low capacity scenario $\left(P^{P e a k, L}\right)$ is much larger than the difference in the off-peak price between the high capacity scenario $\left(P^{O f f-P e a k, H}\right)$ and the low capacity scenario $\left(P^{O f f-P e a k, L}\right)$. Hence, a policy intervention that shifts the supply schedule to the 'high capacity' scenario should noticeably reduce market power and prices during peak hours while having a smaller effect during off-peak hours.

Consequently, we compare the two series of prices in peak and off-peak periods. Figure 4 illustrates the evolution of monthly averages of predicted day-ahead prices in peak and off-peak

\footnotetext{
${ }^{17} \mathrm{~A}$ different way of interpreting this is that price mark-ups are large during peak periods while they are almost nil in off-peak time, when prices simply reflect the marginal cost of the last plant producing on the merit order, i.e. the highest-cost plant producing.
} 
Figure 4: Monthly averages of predicted peak and off-peak prices

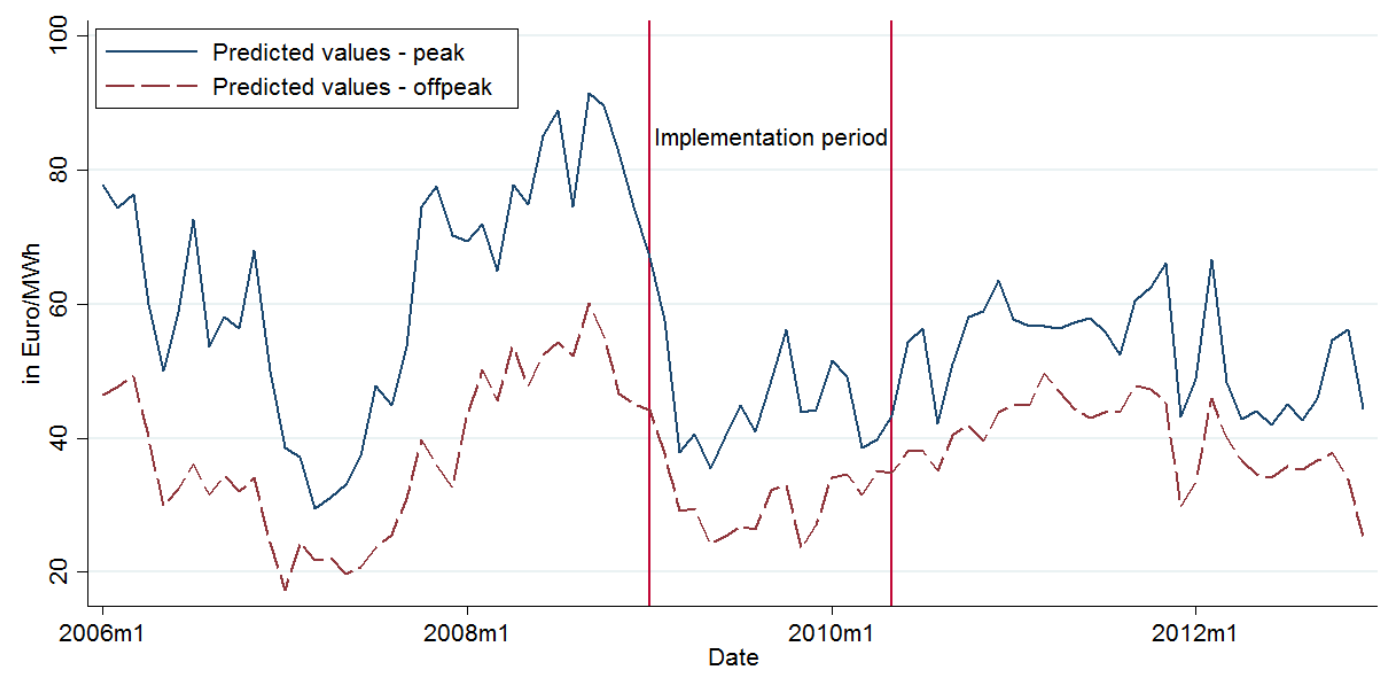

Source: Own calculation based on EPEX price series, 2014

periods. ${ }^{18}$ While there is some seasonal variability, both prices seem to move to a lower level after 2009 and one can also observe convergence between the two series following 2009.

\subsection{Identification of the Treatment Period}

The second crucial element of the identification strategy is the definition of the treatment period; i.e. the time during which we expect the decision's effect to materialize. We start by defining three major periods: the before period (up to December 2008), the implementation period during which the remedies were implemented (January 2009 to May 2010), and the after period (after May 2010). Given the high frequency of electricity trade and because wholesale energy markets are very dynamic, a swift response to changes in supply conditions is expected. Thus, we consider four different impact scenarios that should allow us to identify both the short-term and long-term effects of the policy intervention. The advantage of the short-run scenario is that it identifies the effect of the remedies from a short and well-defined period of time around them. Hence, the risk of contaminating the effect of the intervention with other, unobserved factors is low.

However, it could be that the effects of an important policy intervention are much more pervasive. Therefore, it seems reasonable to also look at long-term effects and to evaluate the impact of the decision over one or more years. The disadvantage of the long-term analysis is that the precise

\footnotetext{
${ }^{18}$ Predicted values are obtained by estimating equation 1 sans post- and treatment indicators. We show monthly averages of predicted values to wash out the volatility of daily prices. A similar, but messier, figure is obtained by plotting daily predicted values or actual prices.
} 
causal identification of the policy intervention is weakened by the likely existence of confounding factors.

\subsubsection{Long Run Effects of the Decisions}

We assume that the Commission's decision had long-lasting effects. We then consider two possible situations. First, we assume that these effects can be observed as soon as the commitments were implemented. Thus, we construct a dummy variable that takes on a value of 1 from the first divestiture onwards including the implementation year 2009:

$$
\text { post }_{t}^{1}= \begin{cases}1 & \text { if date }>\text { Dec } 312008 \\ 0 & \text { if date } \leq \text { Dec } 312008\end{cases}
$$

Alternatively, we assume that the overall effect of the decision can only be observed when the last remedy has been implemented. Thus, we define the post period from the May 32010 onwards and exclude the implementation period from the analysis.

$$
\text { post }_{t}^{2}= \begin{cases}1 & \text { if date }>\text { May } 32010 \\ 0 & \text { if date } \leq \text { Dec } 312008\end{cases}
$$

\subsubsection{The Short-run Effects of the Remedies}

The impact of the divestiture is assumed to be immediate and short-lived. Therefore, the dummy variable post $_{t}^{3}$ takes on the value of 1 for the week after each of the eight divestitures. One week after each divestiture $j$ out of the 8 divestitures, the dummy is switched to zero and turns to 1 again when the next divestiture is implemented.

$$
\text { post }_{t}^{3}= \begin{cases}1 & \text { for } \mathrm{t} \in\left\{t \mid t_{j} \leq t \leq t_{j}+6, j=1 \ldots 8\right\} \\ 0 & \text { else }\end{cases}
$$

where $t_{j}$ designates the date of divestiture $j$. Hence, the coefficient's estimate for this dummy measures the average short term effect of the divestitures.

The above approach assumes that the divestitures only affect prices for one week after their implementation. To relax this assumption, we also estimate the cumulative effects of the remedies by defining a dummy variable for each individual remedy, switching to one after its implementation and remaining one until the end of the sample period. Thus, each of the 8 dummies measures the incremental effect of remedy $j$ over the previous ones:

$$
\text { post }_{t_{j}}^{4}= \begin{cases}1 & \text { for } \mathrm{t} \in\left\{t \mid t \geq t_{j}\right\} \\ 0 & \text { else }\end{cases}
$$


Each coefficient estimate represents the additional impact of the additional remedy implemented at that particular date. The overall effect the remedies at time $t$ is therefore given by the sum of all coefficient estimates up to $t=t_{j}$.

\subsection{Heterogeneity in Treatment}

In the previous discussion, the effect of the divestiture is measured by a binary variable that takes the value one during peak pricing schedules in the evaluation period. We now discuss three dimensions of treatment heterogeneity, which allow us to further qualify our assessment of the short-run impact of the divestitures.

First, while our baseline approach considers all individual divestitures to be equal, the actual generation capacity sold in the individual divestitures varies strongly (see table 2). Clearly, the impact of the divestitures on the market should depend on the amount of divested capacity: as more capacity is divested, the effect should become more pronounced. Therefore, we interact the treatment effect indicator with the capacities divested in the individual plant sales.

Second, divestiture effects are likely to be dependent on the divested technology. Technologies differ in their production costs depending on the fuel type used to generate electricity, which translates into their positioning in the merit order curve. They, therefore, have different likelihoods of being strategically withheld from the market. For example, the marginal cost of power plants running on renewable fuels such as wind or sun is essentially zero. Thus, renewables are less likely to be withdrawn from the market, if at all, than capacities generated by means of other fuels that are higher up the merit order curve. To investigate treatment heterogeneity due to technology types, we interact the treatment indicators with indicators for the type of generation technology divested. Specifically, we differentiate between coal and gas, renewables (including hydro), nuclear and the grid divestiture.

Third, we interact treatment with the identity of the buying firm. While most capacity was sold to domestic firms, some went to foreign firms. While we do not have a strong prior as to differential effects with respect to buyer identity, it could be the case that divestitures to direct competitors have a bigger impact than those to non-domestic firms or grid operators.

\section{Results}

In table 4, we report the main results of the estimation. First, the model fits the data well, as we are able to capture between 63 and $65 \%$ of the variation in wholesale prices. Second, we observe an average difference between peak and off-peak prices that varies from $31-33 € /$ MWh in the long run models, to $24 € / \mathrm{MWh}$ in the short run model. 
Third, the coefficient estimates for the control variables mostly have reasonable signs and sizes. The amount of wind capacity available decreases prices, while the amount of generated wind electricity decreases prices during peak hours and remains insignificant during off-peak hours. The same pattern is observed for solar capacities and the amount of sun per day. The quadratic terms are small and only partially significant. Prices linearly increase and quadratically decrease in both peak and off-peak temperatures. Net cross-border flows decrease peak and (slightly) increase offpeak prices. European market integration seems to have significantly affected prices, as they fell by around 4-5€/MWh after market coupling with Denmark and by a further $5 € /$ MWh after market integration with Belgium, France, the Netherlands, and the remaining Scandinavian countries. While electricity prices significantly increase with gas and emission prices, they do not respond to oil, uranium, or coal prices. Finally, prices increase with the industrial production index and decrease during holidays.

Our main interest, however, lies in the treatment indicators. Their coefficients measure the treatment effect, i.e. the differential evolution of peak prices if compared to off-peak prices after the implementation of the Commission's decision. In the long-run scenarios, we find a significant convergence between peak and off peak prices. This effect is not only statistically, but also economically, significant. In both specifications (post December 2008 or post May 2010 period, excluding the entire implementation period), we observe a significant reduction of peak prices with respect to off-peak prices of around $11 € / \mathrm{MWh}$, other things equal. Considering that off-peak prices can be thought as a rough measure of marginal costs for the highest-cost generator, this result implies that the average peak/off-peak margins are reduced by around 35\% after the implementation of the remedies.

Looking at short-run effects, we also obtain negative and significant coefficient estimates for the dummies measuring the interaction between peak and divestitures, which hint at a short-run price convergence in the week around the implementation of the remedies. In the specification where we assume an average short term effect of the remedies, we find a price convergence of around 5 $€ /$ MWh between peak and off peak prices.

The fourth specification in table 4 reports the findings when individual divestiture dummies are consecutively switched on. In the table, we do not report the cumulative effect but rather the coefficient estimate for the eight individual divestiture dummies. Yet, we are more interested in the overall cumulative effect of the first $n$ divestitures. This is given by the $n^{\text {th }}$ partial sum of the coefficients: e.g. the effect of the third divestiture is given by the sum $\delta_{1}+\delta_{2}+\delta_{3}=$ $-14.6+1.6+1.6=-11.4$. While many individual coefficients are not significantly different from zero, their partial sum is consistently significantly negative. Indeed, the null hypothesis of a zero 
Table 4: The Effect of the Divestitures on German Wholesale Prices

\begin{tabular}{|c|c|c|c|c|c|c|c|c|}
\hline \multirow[b]{2}{*}{ Peak } & \multicolumn{2}{|c|}{ Post 2009} & \multicolumn{2}{|c|}{ Post 2010} & \multicolumn{2}{|c|}{ Short-run } & \multicolumn{2}{|c|}{$\begin{array}{l}\text { Short-run } \\
\text { cumulative }\end{array}$} \\
\hline & $31.18^{* * *}$ & $(1.77)$ & $32.52^{* * *}$ & $(2.08)$ & $23.62^{* * *}$ & $(1.26)$ & $31.88^{* * *}$ & $(1.87)$ \\
\hline Peak*Post & $-11.35^{* * *}$ & $(1.40)$ & $-11.20^{* * *}$ & $(1.42)$ & $-5.39^{* * *}$ & $(2.01)$ & & \\
\hline Peak*Div1 & & & & & & & $-14.59^{* * *}$ & $(2.25)$ \\
\hline Peak*Div2 & & & & & & & 1.55 & $(2.37)$ \\
\hline Peak*Div3 & & & & & & & 1.59 & $(2.51)$ \\
\hline Peak*Div4 & & & & & & & $7.17^{* *}$ & $(3.48)$ \\
\hline Peak*Div5 & & & & & & & -2.52 & $(3.51)$ \\
\hline Peak*Div6 & & & & & & & $-11.16^{* * *}$ & $(2.91)$ \\
\hline Peak*Div7 & & & & & & & $6.15^{* *}$ & $(2.69)$ \\
\hline Peak*Div8 & & & & & & & 0.54 & $(1.85)$ \\
\hline wind_cap & $-7.10^{* *}$ & $(3.24)$ & -7.29 & $(5.24)$ & $-7.39^{* *}$ & $(3.20)$ & $-7.49^{* *}$ & $(3.66)$ \\
\hline wind $_{1}$ & $-0.00^{* * *}$ & $(0.00)$ & $-0.00^{* * *}$ & $(0.00)$ & $-0.00^{* * *}$ & $(0.00)$ & $-0.00^{* * *}$ & $(0.00)$ \\
\hline $\operatorname{wind}_{0}$ & 0.00 & $(0.00)$ & 0.00 & $(0.00)$ & 0.00 & $(0.00)$ & 0.00 & $(0.00)$ \\
\hline wind $_{1}^{2}$ & $0.00^{* * *}$ & $(0.00)$ & $0.00^{* *}$ & $(0.00)$ & $0.00^{* * *}$ & $(0.00)$ & $0.00^{* * *}$ & $(0.00)$ \\
\hline $\operatorname{wind}_{0}^{2}$ & $-0.00^{* *}$ & $(0.00)$ & $-0.00^{* *}$ & $(0.00)$ & $-0.00^{* *}$ & $(0.00)$ & $-0.00^{* *}$ & $(0.00)$ \\
\hline solar_cap & $-1.94^{* * *}$ & $(0.45)$ & $-1.59^{* *}$ & $(0.67)$ & $-1.84^{* * *}$ & $(0.46)$ & $-1.66^{* * *}$ & $(0.54)$ \\
\hline $\operatorname{sun}_{1}$ & $-0.01^{* * *}$ & $(0.00)$ & $-0.01^{* *}$ & $(0.01)$ & $-0.01^{* * *}$ & $(0.00)$ & $-0.01^{* * *}$ & $(0.00)$ \\
\hline $\operatorname{sun}_{0}$ & -0.01 & $(0.02)$ & -0.01 & $(0.02)$ & -0.01 & $(0.02)$ & -0.02 & $(0.02)$ \\
\hline $\operatorname{sun}_{1}^{2}$ & $0.00^{* *}$ & $(0.00)$ & $0.00^{* *}$ & $(0.00)$ & $0.00^{* * *}$ & $(0.00)$ & $0.00^{* * *}$ & $(0.00)$ \\
\hline $\operatorname{sun}_{0}^{2}$ & 0.00 & $(0.00)$ & 0.00 & $(0.00)$ & 0.00 & $(0.00)$ & 0.00 & $(0.00)$ \\
\hline temp $_{1}$ & $-1.63^{* * *}$ & $(0.32)$ & $-1.88^{* * *}$ & $(0.41)$ & $-1.56^{* * *}$ & $(0.32)$ & $-1.72^{* * *}$ & $(0.34)$ \\
\hline temp $_{0}$ & $-0.50^{* * *}$ & $(0.13)$ & $-0.48^{* * *}$ & $(0.16)$ & $-0.63^{* * *}$ & $(0.14)$ & $-0.46^{* * *}$ & $(0.13)$ \\
\hline temp $p_{1}^{2}$ & $0.06^{* * *}$ & $(0.02)$ & $0.07^{* * *}$ & $(0.02)$ & $0.05^{* * *}$ & $(0.02)$ & $0.06^{* * *}$ & $(0.02)$ \\
\hline temp ${ }_{0}^{2}$ & $0.03^{* * *}$ & $(0.01)$ & $0.03^{* * *}$ & $(0.01)$ & $0.03^{* * *}$ & $(0.01)$ & $0.03^{* * *}$ & $(0.01)$ \\
\hline $\mathrm{cb}_{1}$ & $-0.00^{* * *}$ & $(0.00)$ & $-0.00^{* * *}$ & $(0.00)$ & $-0.00^{* * *}$ & $(0.00)$ & $-0.00^{* * *}$ & $(0.00)$ \\
\hline $\mathrm{cb}_{0}$ & $0.00^{* *}$ & $(0.00)$ & $0.00^{* * *}$ & $(0.00)$ & 0.00 & $(0.00)$ & $0.00^{* *}$ & $(0.00)$ \\
\hline coupling & $-4.51^{* *}$ & $(2.14)$ & 120.45 & (.) & $-4.57^{* *}$ & $(2.13)$ & $-4.40^{*}$ & $(2.52)$ \\
\hline coupling2 & $-4.61^{* *}$ & $(2.10)$ & $-5.42^{* *}$ & $(2.44)$ & $-5.01^{* *}$ & $(2.37)$ & $-5.04^{* *}$ & $(2.13)$ \\
\hline oil & 0.03 & $(0.04)$ & -0.02 & $(0.05)$ & 0.04 & $(0.04)$ & -0.00 & $(0.05)$ \\
\hline gas & $1.06^{* * *}$ & $(0.14)$ & $1.04^{* * *}$ & $(0.16)$ & $1.07^{* * *}$ & $(0.14)$ & $1.03^{* * *}$ & $(0.14)$ \\
\hline uranium & -0.05 & $(0.04)$ & -0.04 & $(0.04)$ & -0.05 & $(0.04)$ & -0.04 & $(0.04)$ \\
\hline emissions & $0.31^{* *}$ & $(0.12)$ & $0.40^{* *}$ & $(0.19)$ & $0.38^{* * *}$ & $(0.12)$ & $0.44^{* * *}$ & $(0.15)$ \\
\hline coal & 0.03 & $(0.04)$ & 0.05 & $(0.05)$ & 0.03 & $(0.04)$ & 0.04 & $(0.05)$ \\
\hline holiday & $-12.66^{* * *}$ & $(1.74)$ & $-13.58^{* * *}$ & $(2.03)$ & $-12.38^{* * *}$ & $(1.70)$ & $-12.70^{* * *}$ & $(1.72)$ \\
\hline ind_index & $0.63^{* * *}$ & $(0.18)$ & $0.80^{* * *}$ & $(0.23)$ & $0.60^{* * *}$ & $(0.19)$ & $0.81^{* * *}$ & $(0.20)$ \\
\hline Constant & 66.51 & $(58.15)$ & 51.05 & $(85.23)$ & 77.65 & $(57.91)$ & 53.24 & $(63.77)$ \\
\hline $\mathrm{R}^{2}$ & 0.65 & & 0.63 & & 0.63 & & 0.65 & \\
\hline $\mathrm{N}$ & 5114 & & 4142 & & 5114 & & 5114 & \\
\hline
\end{tabular}

Notes: Standard errors in parentheses, ${ }^{*} \mathrm{p}<0.1,{ }^{* *} \mathrm{p}<0.05,{ }^{* * *} \mathrm{p}<0.01$. 
cumulative effect on prices can be rejected for all but the fourth partial sum, where the effect is insignificant with $p=0.15$. The long-term cumulative effect of all remedies together is then represented by the sum of all coefficients and it is equal to $-11.28 € / \mathrm{MWh}(p=0)$, which is almost exactly identical to the long-term effect measured in the long-term specification.

The comparison of these various approaches gives us a quite coherent picture, pointing to an increase in competition in the market that can be related to the abuse of dominance case. Our results suggest that around the divestitures, the short-run and long-run difference between peak and off-peak prices was, ceteris paribus, significantly reduced. This finding is consistent with the Commission's decision effectively stopping or at least reducing the alleged abuse of market power. The exact extent of this convergence differs, depending on the assumption we make regarding the timing framework, varying between 5 and $11 € / \mathrm{MWh}$.

\subsection{Heterogenous Effects}

Next, we explore dimensions of heterogeneity in the treatment effects, namely differences due to technology types, buyer identities, and the amount of generation capacity divested. Table 5 reports the results. The specification is equivalent to the third specification of table 4, i.e. average short-run effects. ${ }^{19}$

In column (1), we find that the average short-run treatment effect remains significant when we weigh divestitures with the capacity divested. The coefficient's estimate can be interpreted as the average per MW impact of a divestiture: on average prices decreased by 0.6 euro cents per divested MW. In column (2) we interact divestitures with technology types and find that only the divestiture of coal and gas plants significantly decreases prices. The coefficients' estimate for divestitures of renewable and nuclear plants are negative but remain insignificant. When weighing divestitures with capacities (column 3), this finding is confirmed and the precision of the coal and gas coefficient increases. Thus, only the technology types higher up the merit order curve, which are most likely to be strategically withheld from production, impacted prices. This finding increases our confidence that we are indeed identifying the competitive effect of the divestitures.

Column (4) differentiates buyer identities and shows that only transactions involving EnBW (2 acquisitions) and Statkraft (1 acquisition) led to significant price decreases. The capacityweighted results confirm this. The largest per-MW effect is due to the divestitures to EnBW, a close competitor of E.ON. The transactions involving Electrabel (a Belgian generation company), Morgan Stanley (an investment company), TenneT (a Dutch grid operator), and Verbund (an Austrian generator) did not entail significant price reductions. Since the transaction involving

\footnotetext{
${ }^{19}$ Heterogeneous treatment effects cannot be estimated in the long-run scenarios. We obtain similar results estimating cumulative effects, i.e. the fourth specification of table 4 .
} 
Table 5: Heterogenous Effects

\begin{tabular}{|c|c|c|c|c|c|}
\hline & Short-run $\times$ Cap & Fuel & Fuel $\times$ Cap & Buyer & Buyer $\times$ Cap \\
\hline Peak & $\begin{array}{c}23.59^{* * *} \\
(1.256)\end{array}$ & $\begin{array}{c}23.67^{* * *} \\
(1.257)\end{array}$ & $\begin{array}{c}23.70^{* * *} \\
(1.255)\end{array}$ & $\begin{array}{c}23.72^{* * *} \\
(1.272)\end{array}$ & $\begin{array}{c}23.76^{* * *} \\
(1.276)\end{array}$ \\
\hline Peak*Post & $\begin{array}{c}-0.00593^{* *} \\
(0.00282)\end{array}$ & & & & \\
\hline Peak*Div(Coal\&Gas) & & $\begin{array}{c}-5.629^{* *} \\
(2.746)\end{array}$ & $\begin{array}{c}-0.0122^{* * *} \\
(0.00353)\end{array}$ & & \\
\hline Peak*Div(Renewable) & & $\begin{array}{l}-3.615 \\
(2.295)\end{array}$ & $\begin{array}{l}-0.00772 \\
(0.00707)\end{array}$ & & \\
\hline Peak*Div(Nuclear) & & $\begin{array}{l}-0.514 \\
(3.470)\end{array}$ & $\begin{array}{c}-0.000358 \\
(0.00231)\end{array}$ & & \\
\hline Peak*Div(Grid) & & $\begin{array}{c}0.949 \\
(1.799)\end{array}$ & $\begin{array}{c}0.00211 \\
(0.00432)\end{array}$ & & \\
\hline Peak*Div(Electrabel) & & & & $\begin{array}{l}-5.253 \\
(3.400)\end{array}$ & $\begin{array}{l}-0.00336 \\
(0.00287)\end{array}$ \\
\hline $\operatorname{Peak}^{*} \operatorname{Div}($ EnBW $)$ & & & & $\begin{array}{c}-8.247^{* *} \\
(3.997)\end{array}$ & $\begin{array}{c}-0.0144^{* * *} \\
(0.00465)\end{array}$ \\
\hline Peak*Div(MorgStan) & & & & $\begin{array}{c}0.112 \\
(2.060)\end{array}$ & $\begin{array}{c}0.000322 \\
(0.00776)\end{array}$ \\
\hline Peak*Div(Statkraft) & & & & $\begin{array}{c}-9.211^{* * *} \\
(3.258)\end{array}$ & $\begin{array}{c}-0.0123^{* * *} \\
(0.00433)\end{array}$ \\
\hline Peak*Div(TenneT) & & & & $\begin{array}{c}0.960 \\
(1.805)\end{array}$ & $\begin{array}{c}0.00219 \\
(0.00435)\end{array}$ \\
\hline Peak*Div(Verbund) & & & & $\begin{array}{l}-3.092 \\
(1.959) \\
\end{array}$ & $\begin{array}{l}-0.00978 \\
(0.00627)\end{array}$ \\
\hline $\mathrm{R}^{2}$ & 0.63 & 0.63 & 0.63 & 0.63 & 0.63 \\
\hline $\mathrm{N}$ & 5114 & 5114 & 5114 & 5114 & 5114 \\
\hline
\end{tabular}

Notes: Standard errors in parentheses, ${ }^{*} \mathrm{p}<0.1,{ }^{* *} \mathrm{p}<0.05,{ }^{* * *} \mathrm{p}<0.01$. 
TenneT included the grid divestiture, the insignificance of the event could be seen as a corroboration of our assumption that this is a second-order effect.

\subsection{Placebo test: Effect on different markets}

To further support our identification strategy, we conduct placebo tests using data from six other European countries: France is similar to Germany in size, but uses a rather different energy mix. Spain is similar in both size and energy mix. Portugal, Poland, Sweden, and Norway's energy markets are quite distinct from central European energy markets along different dimensions including size, energy mix, as well as economic development and industrial structure. We have relatively good information on prices and control variables for these countries. While renewables feed-in data is only available for Portugal and Spain, and cross-border flows are only available for France, we have data on energy consumption, solar and wind capacities, temperatures, and holidays for all countries considered.

We implement the same identification strategy used for the German market by comparing peak and off-peak prices and using the same definition of the before and after periods. The logic of the placebo test is the following: if we are indeed measuring the effect of the E.ON decision and the German market is not strongly integrated with the others (which should be the case for all but France), then we should not observe treatment effects in these markets. Thus, we expect the Commission's decision not to have significant effects on most other markets. We report the findings of the placebo analysis in table 6 .

The four specifications (post 2009, post 2010, short-run, and short-run cumulative) of table 4 are reported in panels A, B, C, and D of table 6, respectively. Portugal and Sweden have fewer observations than the other countries because we lack renewables feed-in and price data for 2012 .

In most countries, the difference between peak and off-peak prices is lower than in Germany: the difference amounts to around $13-20 €$ in Spain, around $4-6 €$ in Portugal, $12-13 €$ in Poland, 8-12 $€$ in Sweden, and no significant difference in Norway. The exception is France, where the peak/off-peak gap is considerably larger than in Germany.

In the post 2009 specification, we find a significant convergence of peak and off-peak prices for France, Spain, Portugal, and Poland, but not for Sweden and Norway. The effects in the post 2010 scenario are similar, but now also Portugal is not significantly affected. Thus, the convergence of peak and off-peak prices over the 2010 - 2012 period is not unique to Germany. However, and most importantly for our identification strategy, none of the effects on the other countries are as large as the effect in Germany. Both in absolute and in relative terms, price convergence is estimated to be much more pronounced in Germany than in the six placebo markets considered. To exemplify, the 
Table 6: Placebo runs for France, Spain, Portugal, Poland, Sweden and Norway

\begin{tabular}{|c|c|c|c|c|c|c|}
\hline \multirow[t]{2}{*}{ Panel A } & \multicolumn{6}{|c|}{ Post 2009} \\
\hline & France & Spain & Portugal & Poland & Sweden & Norway \\
\hline \multirow[t]{2}{*}{ Peak } & $48.75^{* * *}$ & $15.77^{* * *}$ & $6.073^{* *}$ & $12.95^{* * *}$ & $10.93^{* * *}$ & $\bar{~} 4.614$ \\
\hline & $(6.333)$ & $(3.187)$ & $(2.829)$ & $(1.002)$ & $(2.189)$ & (4.118) \\
\hline \multirow[t]{2}{*}{ Peak*Post } & $-9.510^{* * *}$ & $-4.262^{* * *}$ & $-1.893^{*}$ & $-2.043^{* *}$ & 1.497 & 1.660 \\
\hline & $(1.856)$ & $(0.916)$ & (1.031) & $(0.827)$ & $(1.732)$ & $(1.592)$ \\
\hline $\mathrm{R}^{2}$ & 0.44 & 0.70 & 0.78 & 0.74 & 0.37 & 0.57 \\
\hline \multirow[t]{2}{*}{ Panel B } & \multicolumn{6}{|c|}{ Post 2010} \\
\hline & France & Spain & Portugal & Poland & Sweden & Norway \\
\hline \multirow[t]{2}{*}{ Peak } & $53.64^{* * *}$ & $19.35^{* * *}$ & $6.159^{* *}$ & $12.99^{* * *}$ & $8.112^{\text {*** }}$ & 4.031 \\
\hline & $(7.919)$ & $(3.785)$ & $(2.826)$ & (1.093) & $(1.507)$ & $(3.230)$ \\
\hline \multirow[t]{2}{*}{ Peak*Post } & $-10.33^{* * *}$ & $-3.906^{* * *}$ & -1.487 & $-1.607^{*}$ & 1.040 & 1.863 \\
\hline & $(1.784)$ & $(0.988)$ & (1.082) & $(0.860)$ & $(2.102)$ & $(1.713)$ \\
\hline $\mathrm{R}^{2}$ & 0.57 & 0.66 & 0.73 & 0.75 & 0.62 & 0.60 \\
\hline \multirow[t]{2}{*}{ Panel C } & \multicolumn{6}{|c|}{ Short-run } \\
\hline & France & Spain & Portugal & Poland & Sweden & Norway \\
\hline \multirow[t]{2}{*}{ Peak } & $\overline{241.46^{* * *}}$ & $12.65^{\text {*** }}$ & 4.290 & $111.79^{* * *}$ & $11.66^{* * *}$ & 5.625 \\
\hline & $(6.239)$ & $(3.172)$ & $(2.641)$ & $(0.742)$ & $(2.284)$ & $(3.983)$ \\
\hline \multirow[t]{2}{*}{ Peak*Post } & 14.08 & -3.037 & -2.038 & -1.287 & 0.340 & 1.265 \\
\hline & (18.69) & $(2.613)$ & (2.199) & $(1.273)$ & $(5.670)$ & $(5.427)$ \\
\hline $\mathrm{R}^{2}$ & 0.44 & 0.69 & 0.78 & 0.74 & 0.37 & 0.57 \\
\hline \multirow[t]{2}{*}{ Panel D } & \multicolumn{6}{|c|}{ Short-run cumulative } \\
\hline & France & Spain & Portugal & Poland & Sweden & Norway \\
\hline \multirow[t]{2}{*}{$\overline{\text { Peak }}$} & $51.64^{* * *}$ & $17.11^{* * *}$ & $6.168^{* *}$ & $12.94^{* * *}$ & $9.432^{* * *}$ & 4.240 \\
\hline & $(6.730)$ & $(3.175)$ & $(2.847)$ & $(1.043)$ & $(1.648)$ & $(3.594)$ \\
\hline \multirow[t]{2}{*}{ Peak*Div1 } & $-10.27^{* * *}$ & $-5.492^{* * *}$ & $-3.883^{* *}$ & -1.848 & $-3.914^{*}$ & 0.0552 \\
\hline & $(2.132)$ & $(1.348)$ & $(1.573)$ & $(1.623)$ & $(2.250)$ & $(1.975)$ \\
\hline \multirow[t]{2}{*}{ Peak*Div2 } & -1.301 & -0.878 & 1.891 & -0.745 & $6.574^{* *}$ & 1.830 \\
\hline & $(3.572)$ & $(1.737)$ & $(1.584)$ & $(1.622)$ & $(2.853)$ & $(2.810)$ \\
\hline \multirow[t]{2}{*}{ Peak*Div3 } & $9.601^{* * *}$ & 2.112 & 0.373 & 0.0964 & -2.987 & -1.296 \\
\hline & $(3.290)$ & $(1.315)$ & $(1.082)$ & $(0.851)$ & $(2.357)$ & $(2.288)$ \\
\hline \multirow[t]{2}{*}{ Peak*Div4 } & 70.04 & 0.347 & -0.159 & 0.667 & 2.298 & 0.519 \\
\hline & $(59.86)$ & $(1.297)$ & $(1.091)$ & $(1.164)$ & $(2.033)$ & $(1.548)$ \\
\hline \multirow[t]{2}{*}{ Peak*Div5 } & -77.43 & 0.825 & 0.681 & -1.030 & 1.932 & -0.206 \\
\hline & $(60.20)$ & $(2.195)$ & (1.791) & (1.444) & $(4.654)$ & $(1.786)$ \\
\hline \multirow[t]{2}{*}{ Peak*Div6 } & $-8.902^{* *}$ & -0.953 & -1.531 & -0.119 & 20.20 & 4.873 \\
\hline & $(4.194)$ & $(2.254)$ & $(2.319)$ & $(1.482)$ & (17.63) & $(7.267)$ \\
\hline \multirow[t]{2}{*}{ Peak*Div7 } & 6.419 & -1.608 & -0.711 & $-2.978^{*}$ & -22.96 & -5.598 \\
\hline & $(4.588)$ & (3.405) & $(3.280)$ & $(1.562)$ & (16.16) & (7.937) \\
\hline \multirow[t]{2}{*}{ Peak*Div8 } & 1.519 & 1.738 & 1.847 & $4.322^{* * *}$ & -0.561 & 1.688 \\
\hline & $(2.473)$ & (3.069) & (2.985) & $(0.927)$ & $(6.175)$ & (5.598) \\
\hline $\mathrm{R}^{2}$ & 0.47 & 0.72 & 0.78 & 0.75 & 0.40 & 0.61 \\
\hline $\mathrm{N}$ & 5114 & 5114 & 4340 & 5114 & 4260 & 5114 \\
\hline
\end{tabular}

Notes: Standard errors in parentheses, ${ }^{*} \mathrm{p}<0.1,{ }^{* *} \mathrm{p}<0.05,{ }^{* * *} \mathrm{p}<0.01$. 
largest significant convergence in relative terms observed in the other countries was around $19 \%$ in France, which is considerably less than the $35 \%$ convergence measured in Germany. ${ }^{20}$

Thus, the long-run market power reduction estimated for Germany lies well above the largest reductions observed in the same period in other European countries. This enhances our confidence that we identify the effect of the analyzed remedies.

In the short-run specification, where treatment evaluation is tailored around the individual divestitures in Germany, we do not find any significant effects on the six other countries. In the cumulative effects specifications, we find that on average three of the eight partial sums are significantly negative (compared to seven out of eight in Germany) and that effects on average sum up to $-2.43 €$ (compared to $-11.28 €$ in Germany).

Finally, we also estimate year-specific effects on the peak/off-peak spread over the 2009-2012 evaluation period. The absolute effects are largest in Germany in each year, ranging from $10-13$ $€$ (i.e. similar to the ATEs reported in table 4. In figure 5, we plot the change of the spread relative to the pre-treatment level. The figure shows that the spread declines in all Continental European countries, but strongly increases for the Scandinavian countries in 2010. The German peak/off-peak price gap was reduced by $34 \%$ in 2009 , by $41 \%$ in 2010 , by $39 \%$ in 2011 , and by $32 \%$ in 2012. These are the largest reductions across all seven countries considered, except for 2009, where Portugal lies slightly below Germany.

In summary, we find that peak and off-peak prices have also converged in other Continental European countries, but not in Scandinavian countries. However, the extent of convergence is by far the largest in Germany, both in absolute terms and relative to the pre-existing gap, across all specifications and countries considered. Further, we find little to no short-run effects in other countries. Looking at year-specific effects, we find that price convergence in Germany envelopes that in other countries from below.

\subsection{Placebo test: Effect in different treatment periods}

In this section, we report the findings of two time placebo trials, where we shift the evaluation period to a time period when no actual treatment occurred. We limit the dataset to the pre-treatment period (2006 - 2008) and consider two scenarios: first, we assume that the 'treatment' started in 2007 , such that 2006 is the pre-treatment period and 2007 and 2008 constitute the evaluation period; second, we let 'treatment' start in 2008 and evaluate its impact during that year. We move the dates of the individual divestitures forward by two and one year(s) respectively. In the second

\footnotetext{
${ }^{20}$ Interpreting this result in a sort of difference-in-difference-in-difference exercise, we can say that in the worst case scenario the 'true' treatment effect is equal to the difference between the German convergence and the French convergence. Hence, the lower bound for the long-run effect of the divestiture is a $16 \%$ reduction of the spread between peak and off-peak prices.
} 
Figure 5: Year-specific effects on peak/offpeak spread: Germany and placebos

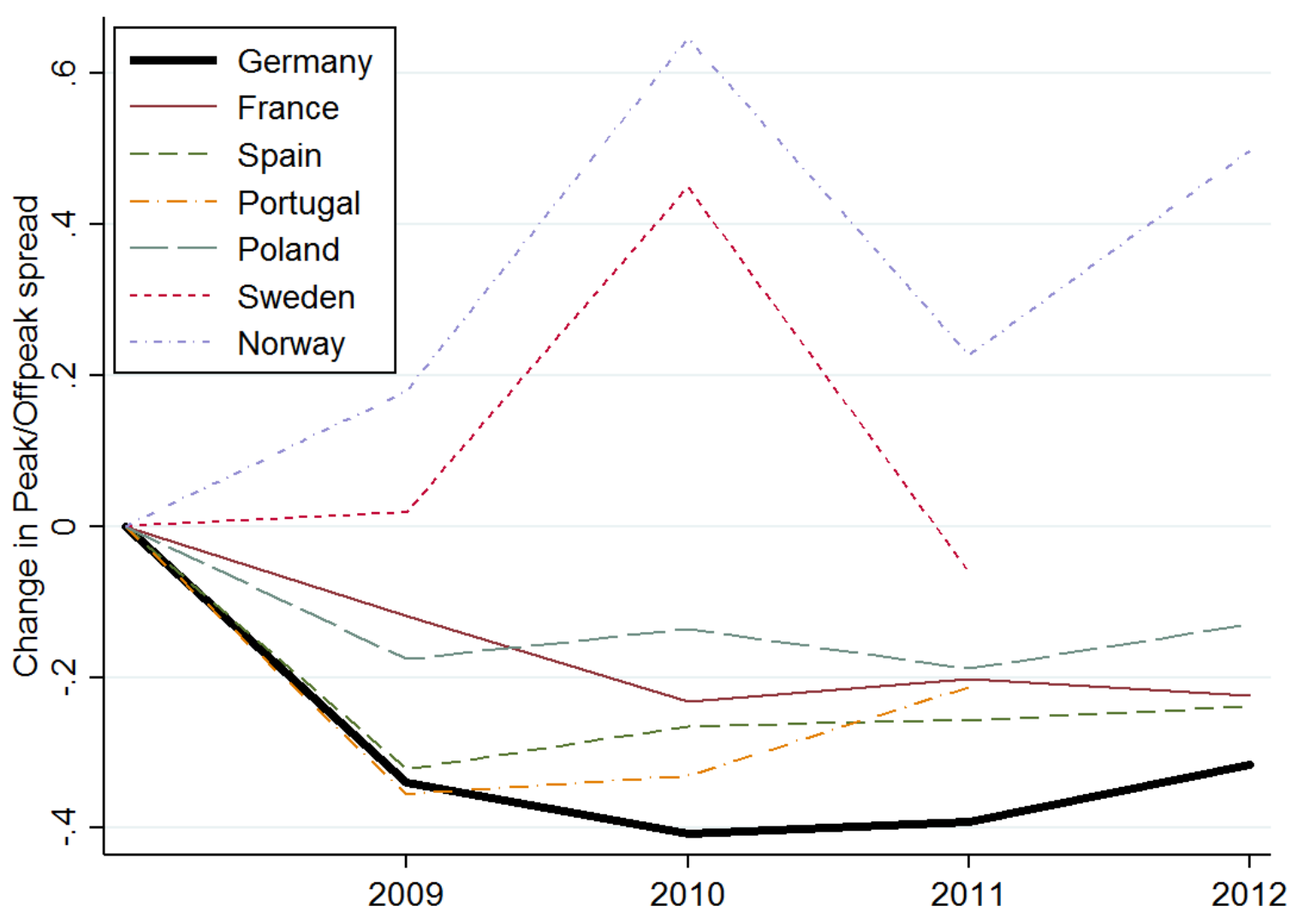


scenario, two divestitures are dropped because moving them forward by one year only would leave them in the actual treatment period (see table 2). We report the findings in table 7.

In both scenarios, we find no significantly negative long-run convergence effects (columns 1 and 4 of table 7), in 2008 the gap even significantly increased. The short-run specifications (columns 2 and 5) show no significant effects around the pre-dated divestitures. The cumulative effects specifications (columns 3 and 6) show some significant coefficients, but in both cases the partial sums alternate between positive and negative significance, showing no clear pattern.

Table 7: Time placebos in pre-treatment period

\begin{tabular}{|c|c|c|c|c|c|c|}
\hline & \multicolumn{3}{|c|}{ Treatment period $2007-2008$} & \multicolumn{3}{|c|}{ Treatment period 2008} \\
\hline & Post 2006 & $\begin{array}{c}\text { Short-run } \\
\text { pooled }\end{array}$ & $\begin{array}{l}\text { Short-run } \\
\text { cumulative }\end{array}$ & Post 2007 & $\begin{array}{c}\text { Short-run } \\
\text { pooled }\end{array}$ & $\begin{array}{l}\text { Short-run } \\
\text { cumulative }\end{array}$ \\
\hline Peak & $\begin{array}{c}34.85^{* * *} \\
(4.654)\end{array}$ & $\begin{array}{c}35.70^{* * *} \\
(3.384)\end{array}$ & $\begin{array}{c}31.22^{* * *} \\
(3.850)\end{array}$ & $\begin{array}{c}32.74^{* * *} \\
(3.846)\end{array}$ & $\begin{array}{c}35.26^{* * *} \\
(3.419)\end{array}$ & $\begin{array}{c}33.67^{* * *} \\
(3.610)\end{array}$ \\
\hline Peak*Post & $\begin{array}{c}0.909 \\
(3.050)\end{array}$ & $\begin{array}{l}-1.251 \\
(4.271)\end{array}$ & & $\begin{array}{c}6.129^{* * *} \\
(2.371)\end{array}$ & $\begin{array}{c}5.861 \\
(5.068)\end{array}$ & \\
\hline Peak*Div1 & & & $\begin{array}{c}-6.714^{* *} \\
(3.067)\end{array}$ & & & $\begin{array}{c}2.506 \\
(3.026)\end{array}$ \\
\hline Peak*Div2 & & & $\begin{array}{l}-3.209 \\
(4.940)\end{array}$ & & & $\begin{array}{c}2.285 \\
(4.363)\end{array}$ \\
\hline Peak*Div3 & & & $\begin{array}{c}0.234 \\
(4.409)\end{array}$ & & & $\begin{array}{l}-1.881 \\
(5.397)\end{array}$ \\
\hline Peak*Div4 & & & $\begin{array}{c}3.546 \\
(5.858)\end{array}$ & & & $\begin{array}{l}15.73^{* *} \\
(6.617)\end{array}$ \\
\hline Peak*Div5 & & & $\begin{array}{c}23.79^{* * *} \\
(4.938)\end{array}$ & & & $\begin{array}{c}-9.994^{* *} \\
(5.041)\end{array}$ \\
\hline Peak*Div6 & & & $\begin{array}{c}-16.45^{* * *} \\
(4.991)\end{array}$ & & & $\begin{array}{c}-33.34^{* * *} \\
(6.818)\end{array}$ \\
\hline Peak*Div7 & & & $\begin{array}{c}0.808 \\
(3.733)\end{array}$ & & & $\begin{array}{c}0 \\
(.)\end{array}$ \\
\hline Peak*Div8 & & & $\begin{array}{r}3.738 \\
(4.652) \\
\end{array}$ & & & $\begin{array}{c}0 \\
(.)\end{array}$ \\
\hline $\mathrm{R}^{2}$ & 0.64 & 0.64 & 0.67 & 0.64 & 0.64 & 0.66 \\
\hline $\mathrm{N}$ & 2192 & 2192 & 2192 & 2192 & 2192 & 2192 \\
\hline
\end{tabular}

Notes: Standard errors in parentheses, ${ }^{*} \mathrm{p}<0.1,{ }^{* *} \mathrm{p}<0.05,{ }^{* * *} \mathrm{p}<0.01$.

\section{Robustness}

\subsection{Autocorrelation of Errors \& Data Frequency}

Autocorrelation in the residuals is one of the main econometric issues we face with high frequency, time-series, data. The use of a Newey-West estimator for the standard errors addresses this issue. However, we try different specifications to understand the extent of the potential problem. First, 
we use a Newey-West estimator with lower order autocorrelation lags (two days). We report our findings in table 8. Results are almost identical to those reported in our main specification and none of the coefficients lose statistical significance.

Table 8: Second-order Autocorrelation

\begin{tabular}{|c|c|c|c|c|}
\hline & Post 2009 & Post 2010 & Short-run pooled & Short-run cumulative \\
\hline \multirow[t]{2}{*}{ Peak } & $31.25^{* * *}$ & $32.61^{* * *}$ & $23.68^{* * *}$ & $32.03^{* * *}$ \\
\hline & $(1.496)$ & $(1.785)$ & $(1.077)$ & $(1.598)$ \\
\hline \multirow[t]{2}{*}{ Peak*Post } & $-11.37^{* * *}$ & $-11.19^{* * *}$ & $-5.411^{* * *}$ & \\
\hline & $(1.101)$ & $(1.129)$ & $(1.775)$ & \\
\hline \multirow[t]{2}{*}{ Peak*Div1 } & & & & $-14.71^{* * *}$ \\
\hline & & & & $(1.935)$ \\
\hline \multirow[t]{2}{*}{ Peak*Div2 } & & & & 1.574 \\
\hline & & & & $(2.203)$ \\
\hline \multirow[t]{2}{*}{ Peak*Div3 } & & & & 1.665 \\
\hline & & & & $(2.129)$ \\
\hline \multirow[t]{2}{*}{ Peak*Div4 } & & & & $7.141^{* *}$ \\
\hline & & & & $(2.891)$ \\
\hline \multirow[t]{2}{*}{ Peak*Div5 } & & & & -2.563 \\
\hline & & & & $(3.041)$ \\
\hline \multirow[t]{2}{*}{ Peak*Div6 } & & & & $-11.16^{* * *}$ \\
\hline & & & & $(2.624)$ \\
\hline \multirow{2}{*}{ Peak*Div7 } & & & & $6.249^{* * *}$ \\
\hline & & & & $(2.349)$ \\
\hline \multirow{2}{*}{ Peak*Div8 } & & & & 0.495 \\
\hline & & & & $(1.577)$ \\
\hline $\mathrm{R}^{2}$ & 0.65 & 0.63 & 0.63 & 0.65 \\
\hline $\mathrm{N}$ & 5114 & 4142 & 5114 & 5114 \\
\hline
\end{tabular}

Notes: Standard errors in parentheses, ${ }^{*} \mathrm{p}<0.1,{ }^{* *} \mathrm{p}<0.05,{ }^{* * *} \mathrm{p}<0.01$.

Second, to account for a more general structure in the autocorrelation of the disturbances, we use a bootstrap estimation with 1,000 replacements to obtain consistent standard errors. Results are reported in table 9 and are again very similar to those reported in our main specification.

Third, we reduce the frequency of the data to a weekly level. We compute the weekly averages for the peak and off-peak prices, as well as all control variables. Results are reported in table 10. Once more, all conclusions from the main analysis are supported. While reducing the size of the dataset by a factor of 7 , neither the coefficients nor their significances are strongly affected.

\subsection{Treatment Time Windows}

When estimating the short-run impact of the divestitures, we chose to define the post-period (the 'treatment window') to be equal to the week following (and including the day of) the divestiture. This seems appropriate, as we expect energy wholesale markets to i) react quickly to changes in 
Table 9: Bootstrapped standard errors

\begin{tabular}{lcccc}
\hline & Post 2009 & Post 2010 & Short-run pooled & Short-run cumulative \\
\hline \hline Peak & $31.25^{* * *}$ & $32.61^{* * *}$ & $23.68^{* * *}$ & $32.03^{* * *}$ \\
Peak*Post & $(1.164)$ & $(1.393)$ & $(0.816)$ & $(1.215)$ \\
& $-11.37^{* * *}$ & $-11.19^{* * *}$ & $-5.411^{* * *}$ & \\
Peak*Div1 & $(0.826)$ & $(0.850)$ & $(1.443)$ & $-14.71^{* * *}$ \\
& & & $(1.546)$ \\
Peak*Div2 & & & 1.574 \\
& & & $(1.921)$ \\
Peak*Div3 & & & 1.665 \\
& & & $(1.915)$ \\
Peak*Div4 & & & $7.141^{* * *}$ \\
& & & $(2.483)$ \\
Peak*Div5 & & & -2.563 \\
& & & $(2.652)$ \\
Peak*Div6 & & & $-11.16^{* * *}$ \\
& & & $(2.062)$ \\
Peak*Div7 & & & $6.249^{* * *}$ \\
Peak*Div8 & & & & $(1.863)$ \\
& & & & 0.495 \\
$\mathrm{R}^{2}$ & & & $1.236)$ \\
$\mathrm{N}$ & & & & 0.65 \\
\hline \hline
\end{tabular}

Notes: Standard errors in parentheses, ${ }^{*} \mathrm{p}<0.1,{ }^{* *} \mathrm{p}<0.05,{ }^{* * *} \mathrm{p}<0.01$. 
Table 10: Aggregating to Weekly Data

\begin{tabular}{|c|c|c|c|c|}
\hline & Post 2009 & Post 2010 & Short-run pooled & Short-run cumulative \\
\hline \multirow[t]{2}{*}{ Peak } & $32.88^{* * *}$ & $34.20^{* * *}$ & $24.72^{* * *}$ & $34.04^{* * *}$ \\
\hline & $(1.996)$ & $(2.301)$ & $(1.472)$ & $(2.124)$ \\
\hline \multirow[t]{2}{*}{ Peak*Post } & $-12.06^{* * *}$ & $-12.09^{* * *}$ & $-6.387^{* *}$ & \\
\hline & $(1.451)$ & $(1.484)$ & $(2.489)$ & \\
\hline Peak*Div1 & & & & $\begin{array}{c}-14.24^{* * *} \\
(2.624)\end{array}$ \\
\hline \multirow[t]{2}{*}{ Peak*Div2 } & & & & 3.197 \\
\hline & & & & $(2.783)$ \\
\hline \multirow[t]{2}{*}{ Peak*Div3 } & & & & -0.989 \\
\hline & & & & $(2.696)$ \\
\hline \multirow[t]{2}{*}{ Peak*Div4 } & & & & $8.933^{* *}$ \\
\hline & & & & $(3.865)$ \\
\hline \multirow[t]{2}{*}{ Peak*Div5 } & & & & -4.585 \\
\hline & & & & (3.693) \\
\hline \multirow[t]{2}{*}{ Peak*Div6 } & & & & $-12.78^{* * *}$ \\
\hline & & & & $(3.609)$ \\
\hline \multirow[t]{2}{*}{ Peak*Div7 } & & & & $7.496^{* *}$ \\
\hline & & & & $(3.492)$ \\
\hline \multirow[t]{2}{*}{ Peak*Div8 } & & & & 0.682 \\
\hline & & & & $(2.433)$ \\
\hline $\mathrm{R}^{2}$ & 0.78 & 0.77 & 0.75 & 0.78 \\
\hline $\mathrm{N}$ & 728 & 590 & 728 & 728 \\
\hline
\end{tabular}

Notes: Standard errors in parentheses, ${ }^{*} \mathrm{p}<0.1,{ }^{* *} \mathrm{p}<0.05,{ }^{* * *} \mathrm{p}<0.01$. 
supply, but also to ii) be quickly influenced by other market factors. In table 11, we change the post period of the individual divestitures to be 2 weeks or 1 month long, respectively.

Table 11: Length of Treatment Windows

\begin{tabular}{lcccc}
\hline & \multicolumn{2}{c}{2 weeks, pooled } & \multicolumn{2}{c}{4 weeks, pooled } \\
\hline \hline Peak & $23.95^{* * *}$ & $(1.518)$ & $24.07^{* * *}$ & $(1.527)$ \\
Peak*Post & $-4.375^{* *}$ & $(1.738)$ & $-3.640^{* *}$ & $(1.442)$ \\
\hline $\mathrm{R}^{2}$ & 0.624 & & 0.625 & \\
$\mathrm{~N}$ & 4382 & 4382 & \\
\hline \hline
\end{tabular}

Notes: Standard errors in parentheses, ${ }^{*} \mathrm{p}<0.1,{ }^{* *} \mathrm{p}<0.05,{ }^{* * *} \mathrm{p}<0.01$.

The coefficient in the pooled estimation decreases from $-5.4 € /$ MWh in our main specification to -4.4 and -3.6 when increasing the treatment windows to 2 weeks and 1 month, respectively. This seems to confirm the intuition that longer windows 'dilute' the effect of the divestiture.

\subsection{Different Definitions of the Peak}

Throughout our analysis, we assume that the peak period starts at $8 \mathrm{am}$ and ends at $8 \mathrm{pm}$. While this seems a reasonable assumption as it measures the average peak price, there might still be quite different price dynamics during the day. Indeed, it is well known that there generally are two high price peaks during the day: around $12 \mathrm{pm}$ and around $6 \mathrm{pm}$. Hence, the convergence effect could non-monotonically depend on the peak definition. As documented by e.g. Kwoka and Sabodash (2011), the incentive to withdraw capacity is particularly high during the hours of highest demand.

As a robustness check, we therefore replicate the main specifications using twelve different definitions of the peak. Instead of using the average daily price, we use the hourly price at different hours of the day from $8 \mathrm{am}$ to $8 \mathrm{pm}$. Figure 6 graphically reports the results of the estimation based on the long-run specification.

The difference between peak and off-peak prices (green dots) substantially varies over the course of the day, reaching its highest values around $12 \mathrm{pm}$ as well as $6 \mathrm{pm}$ to $7 \mathrm{pm}$. The green-shaded area corresponds to the $95 \%$ confidence intervals of the estimated peak coefficients. The green dashed line indicates the average effect of $-11.35 €$ reported in column 1 of table 4 .

Similarly, the treatment effect varies over the course of the day, although to a lesser extent. The largest effect is measured when the peak period is defined as $12 \mathrm{pm}$, where the effect is as large as $21 € /$ MWh. This implies a reduction of the spread between peak and off-peak prices of $53 \%$. This is consistent with the view that the benefits of withdrawing capacity substantially increase with higher demand and that this increase is non-linear.

While these additional estimations show that there is substantial heterogeneity on the estimated size of the convergence depending on the exact definition of the peak time, the figure also confirms 
Figure 6: Estimated peak and treatment effects using single-hour peak definitions

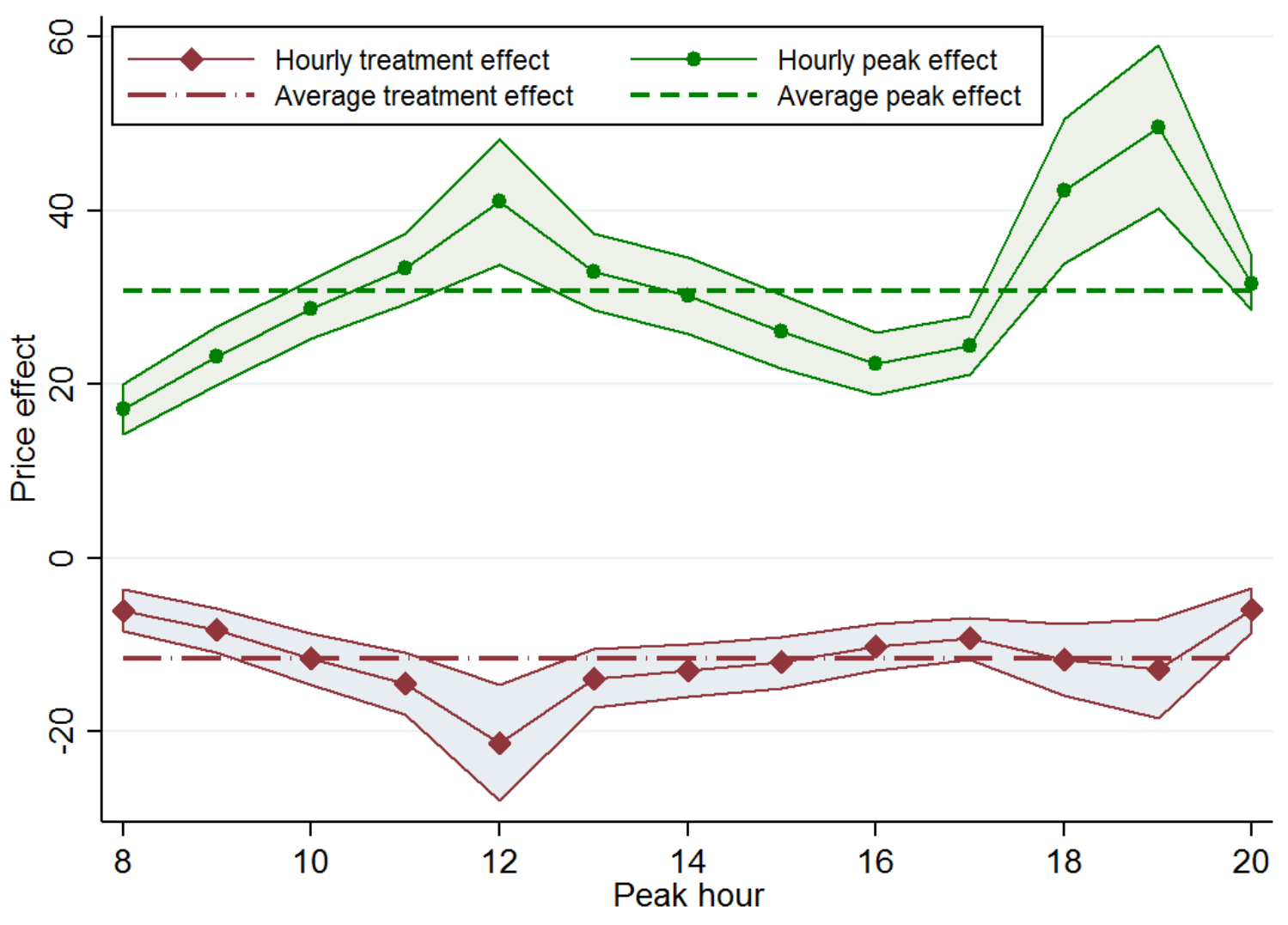


that the qualitative results are not affected by this assumption. Independent of the definition of the peak-hour, we always obtain significant convergence effects. The results reported in our main specification are essentially a conservative estimate of the larger convergence that one could obtain by having a stricter definition of the peak.

\section{Conclusions}

In this paper, we study the effect of a specific competition policy intervention: the EU Commission's case against E.ON for its alleged abuse of dominant position in the German wholesale electricity market. The investigation confirmed the presence of competition concerns and, as a consequence, E.ON committed to divest a total of 5,000 MW of generation capacity as well as its high-voltage transmission network. The focus on a specific case study allows us to be quite precise in modelling the peculiarities of the market and the case, thus providing convincing evidence that our estimates represent the causal effects of the decision. Because the intervention directly affected upstream electricity markets, we study the effect of the Commission's decision on wholesale prices. We adopt a difference-in-difference methodology to identify the effect of the policy intervention.

Our approach and identification strategy are tailored to the specificities of the German electricity market. We exploit the fact that prices are mostly determined through a centralized energy exchange market, the EEX. Although most electricity is traded via over-the-counter contracts, the EEX price is the opportunity cost for energy trading and, therefore, is a good benchmark. The EEX market is also very liquid and swiftly responds to changes in energy supplied and the intensity of competition, which makes it particularly well suited for an empirical analysis.

Our identification is based on the observation that energy suppliers have more market power during peak periods when demand is higher. Since the supply schedule is highly convex and much steeper during the peak period (8am-8pm), shifts to a lower or higher capacity schedule would have larger effects during peak time. Thus, we expect a convergence between peak and off-peak prices if market power is reduced. We estimate a wholesale price equation using daily data on peak and off-peak prices. We control for a large set of relevant determinants of wholesale prices, such as input prices, demand conditions, and supply conditions. Moreover, we carefully control for the evolution of renewables that, due to the regulatory environment, dramatically changed the functioning of German wholesale electricity markets starting from the second half of the 2000s.

We identify the short-run effect of the Commission by looking at convergence between peak and off-peak prices in the weeks around each divestiture, while the long-run effects are identified by looking at the convergence over a period of one or two years after the implementation of the remedies. We find strong and statistically significant convergence effects in the short-run as well as 
in the long-run. The size of the effect is economically relevant, with convergence varying between 5 to $11 € /$ MWh. A large battery of robustness checks corroborate our results. Moreover, placebo regressions based on data from six other European countries as well as different timing for the treatment support our identification strategy. These findings are consistent the view that the Commission's decision, by affecting competition in the EEX market, reduced wholesale prices.

\section{References}

Aguzzoni, L., Argentesi, E., Ciari, L., Duso, T., and Tognoni, M. (2016). Ex post merger evaluation in the uk retail market for books. The Journal of Industrial Economics, 64(1):170-200.

Ashenfelter, O. and Hosken, D. (2010). The effect of mergers on consumer prices: Evidence from five mergers on the enforcement margin. Journal of Law and Economics, 53(3):417-466.

Ashenfelter, O. C., Hosken, D., and Weinberg, M. C. (2014a). Did robert bork understate the competitive impact of mergers? evidence from consummated mergers. Journal of Law and Economics, 57(S3):S67-S100.

Ashenfelter, O. C., Hosken, D., and Weinberg, M. C. (2014b). The price effects of a large merger of manufacturers: A case study of maytag-whirlpool. , American Economics Journal: Economic Policy, 5(1):239-261.

BDEW (2016). BDEW-Strompreisanalyse 2016. BDEW.

Böckers, V. and Heimeshoff, U. (2014). The extent of european power markets. Energy Economics, $46: 102-111$.

Boiteux, M. (1960). Peak-load pricing. The Journal of Business, 33(2):157-179.

Borenstein, S., Bushnell, J. B., and Wolak, F. A. (2002). Measuring market inefficiencies in california's restructured wholesale electricity market. The American Economic Review, 92(5):13761405 .

Bundeskartellamt (2011). Sector Inquiry into Electricity Generation and Wholesale Markets. Bundeskartellamt.

Davies, S. W. and Ormosi, P. L. (2012). A comparative assessment of methodologies used to evaluate competition policy. Journal of Competition Law and Economics, 8(4):769-803.

Duso, T. and Szücs, F. (2017). Market power and heterogenous pass-through in the german retail electricity market. European Economic Review, 98:354-372. 
EEX (2013). Eex-märkte mit starkem wachstum im jahr 2013.

EEX (2015). Eex-gruppe mit starkem volumenwachstum im ersten halbjahr 2015.

Engle, R. F., Mustafa, C., and Rice, J. (1992). Modelling peak electricity demand. Journal of forecasting, 11(3):241-251.

Ilkzkovitz, F. and Dierx, A. (2015). Ex-post economic evaluation of competition policy enforcement: A review of the literature. Technical report, European Commission.

Joskow, P. L. and Kahn, E. (2002). A quantitative analysis of pricing behavior in californiaï£is wholesale electricity market during summer 2000. The Energy Journal, 23(4):1-35.

Just, S. and Weber, C. (2015). Strategic behavior in the german balancing energy mechanism: incentives, evidence, costs and solutions. Journal of Regulatory Economics, 48(2):218-243.

Kwoka, J. and Sabodash, V. (2011). Price spikes in energy markets:ï£business by usual methodsï£i or strategic withholding? Review of Industrial Organization, 38(3):285-310.

Kwoka, J. E. (2013). Does merger control work? a retrospective on us enforcement actions and merger outcomes. Antitrust Law Journal, 78.

Möst, D. and Genoese, M. (2009). Market power in the german wholesale electricity market. The Journal of Energy Markets, 2(2):47.

Müsgens, F. (2006). Quantifying market power in the german wholesale electricity market using a dynamic multi-regional dispatch model. Journal of Industrial Economics, pages 471-498.

Nardi, P. (2012). Transmission network unbundling and grid investments: Evidence from the ucte countries. Utilities Policy, 23:50-58.

Ockenfels, A., Grimm, V., and Zoettl, G. (2008). Strommarktdesign - preisbildungsmechanismus im auktionsverfahren für stromstundenkontrakte an der eex. Gutachten im Auftrag der European Energy Exchange AG zur Vorlage an die Sächsische Börsenaufsicht, 11.

OECD (2016). Reference guide on ex-post evaluation of competition agencies' enforcement decisions. Technical report.

Ormosi, P., Mariuzzo, F., and Richard, H. (2015). A review of merger decisions in the eu: What can we learn from ex-post evaluations? Technical report, European Commission.

Pardo, A., Meneu, V., and Valor, E. (2002). Temperature and seasonality influences on spanish electricity load. Energy Economics, 24(1):55-70. 
Pollitt, M. (2008). The arguments for and against ownership unbundling of energy transmission networks. Energy policy, 36(2):704-713.

Puller, S. L. (2007). Pricing and firm conduct in california's deregulated electricity market. The Review of Economics and Statistics, 89(1):75-87.

Sadowska, M. M. (2011). Energy liberalization in antitrust straitjacket: A plant too far? World Competition: Law and Economics Review, 34(3).

Schwarz, H.-G., Lang, C., and Meier, S. (2007). Market power in the german wholesale electricity market: What are the political options? Available at SSRN 1028201.

Stoft, S. (2002). Power system economics. Journal of Energy Literature, 8:94-99. 